\title{
New Supercoiling Theory and Model of Chromosomal Structures in Eukaryotic Cells
}

Hao Zhang, Tianhu Li*

Division of Chemistry and Biological Chemistry, School of Physical and Mathematical Sciences, Nanyang Technological University, 21 Nanyang Link, Singapore 637371

* Corresponding author

E-mail: thli@ntu.edu.sg

\begin{abstract}
:
About six billion base pairs of DNA reside highly orderly in each human cell's nucleus through their manifestation as twenty-three pairs of chromosomes. Delicate patterns of spatial organizations of DNA macromolecules in these eukaryotic chromosomes as well as their associated driving forces have, however, not been fully understood thus far. On the basis of (1) our four recent discoveries about supercoiling properties of histone $\mathrm{H} 1$, nucleosomes, linker DNA and polynucleosomes, (2) well-established axioms about sign, shapes and handedness of DNA supercoils, as well as (3) the fact that alterations of DNA supercoils are affiliated with every single steps of cellular genetic events, we analyze effects of DNA supercoils on eukaryotic chromosomal structures in systematical and comprehensive manners in the current report, and present new theory and models of eukaryotic chromosomal structures from the DNA supercoiling perspective. It is our hope that our current presentation of new supercoiling theory and models could provoke future new efforts to unravel exquisite eukaryotic chromosomal architectures in an all-inclusive manner.
\end{abstract}

\section{Key words:}

Chromosomes, DNA supercoiling, meiosis and mitosis, interphase and metaphase DNA, chromatin, nucleosomes. 


\section{Introduction}

Supercoiling and its alterations are affiliated at all times with cellular DNA at all levels of life, from prokaryotes, to archaea, and to eukaryotes. ${ }^{1-5}$ During DNA replication and chromosome packaging in eukaryotic cells, for example, histones and topoisomerase II as two of the most abundant supercoiling-associating proteins act on DNA to adjust superhelical densities of genomic DNA in their host cells. ${ }^{6-7}$ In addition, after a transcription process starts in prokaryotic cells, DNA gyrase will emerge to relax positive DNA supercoils that are built up in front of transcription bubbles. ${ }^{8-9}$ Furthermore, DNA macromolecules in all hyperthermophilic archaea exist in their positively supercoiled forms, which are resulted from action of their uniquely own DNA reverse gyrase. ${ }^{10-11}$ These $^{6-11}$ and immense other evidence ${ }^{12-18}$ have demonstrated that DNA supercoiling plays vital roles in the functions of cells in all types of organisms on Earth.

From the structural standpoint, on the other hand, supercoiling of DNA is a physical arrangement of topologically closed double helical structure of nucleic acids that exists in space in an underwound or overwound fashions. ${ }^{1,19-20}$ This topologically closed DNA could (1) either appear as a covalently closed circular entity or (2) possesses non-rotatable terminuses in its linear duplex structures ${ }^{21}$. With the purpose of mathematically describing supercoiling features of DNA, Călugăreanu-White-Fuller Theorem ${ }^{22-25}$ ("DNA Topological Conservation Law") ${ }^{26-27}$ was suggested in the 1960s and 1970s, which is expressed in form of the following equation:

$$
\text { Linking number }=\text { Twist number }+ \text { Writhe number } \quad \text { (Equation } 1)
$$

In view of the fact that vast new knowledge on DNA structures has been acquired since $1960 \mathrm{~s},{ }^{22-25}$ our research group reformulated Călugăreanu-White-Fuller Theorem and presented a new "General Topological Conservation Law of DNA" in 2011 based on experimental data newly obtained in our $1 a b,{ }^{28}$ in which effects of non-canonical structures of DNA were taken into account:

$$
\mathrm{Lk}-\mathrm{Tw}+\mathrm{Nb}=\mathrm{Wb}+\mathrm{Wn}=\mathrm{Wr}
$$

(Equation 2)

In addition, with the purpose of gaining new information about the perplexed spatial organizations of eukaryotic chromosomes, our research group had conducted a series of particularly designed studies in the past two years, from which four new discoveries (Discovery 1 to Discovery 4 as discussed in Section 2.1 below) about supercoiling properties of histone $\mathrm{H} 1$, linker DNA, nucleosomes and polynucleosomes were made. ${ }^{29-32}$ In the current report, on the basis of our recent four discoveries ${ }^{29-32}$ and previously well-established principles about supercoiling properties of DNA, ${ }^{1-2,33-35}$ we present supercoiling theory and views on eukaryotic chromosomal structures from the conceptual and deductive standpoints. It is our hope that our new analyses and deductions could serve as incentives for developing new comprehensive structural models in the future that will unveil secrecy of subtle and sophisticated architectures of eukaryotic chromosomes. 


\section{Our Recent Four Discoveries, Previously Established Axioms about Supercoiling Properties of DNA and Our Three Propositions}

\subsection{Our recent four discoveries}

Discovery 1. Binding of histone $\mathrm{H} 1$ to nucleosomes leads to generation of negative supercoils in naked linker DNA regions of polynucleosomes. ${ }^{29}$

It had been known in the past that upon their mixing-up with histone $\mathrm{H} 1$, loose circular polynucleosomes turned instantaneously into aggregate structures. ${ }^{36-37}$ Our recent studies demonstrated that these aggregate structures were relaxable by E. coli. topoisomerase I (Fig. 1A). ${ }^{29}$ Because the only substrate of $E$. coli. topoisomerase I is negatively supercoiled DNA, our new observations ${ }^{29}$ signified that negative supercoils were produced in the naked DNA regions of polynucleosomes once they were bound by histone H1. In addition, since backbones of supercoiled DNA is forcibly curved, ${ }^{38-39}$ it is evident that backbone curvatures of negatively supercoiled DNA cause polynucleosomes to aggregate. ${ }^{29}$

Discovery 2. Upon binding of histone H1, two 10-base pair arm DNA segments at ends of chromatosome DNA form (1) right handed and (2) toroidal shaped positive supercoils, which is the cause of generation of negative supercoils in their adjacent naked linker DNA regions. ${ }^{30}$

Our recent FRET studies demonstrated that when two 10-base pair arm DNA segments exist in their histone H1-enforced arm-closed forms, the two arms were oriented toward each other $^{30}$ (Fig. 1B). These orientations denote that two 10-base pair arm DNA segments in chromatosomes are right-handed, toroidal shaped positive supercoils. ${ }^{30}$ As compensation of positive supercoils produced in these two 10-base pair arm DNA segments, negative supercoils are generated simultaneously in their adjacent naked linker DNA regions. ${ }^{30}$ In theory, the two 10-base pair arm DNA segments in chromatosomes are able to emerge in their relaxed forms (Structure 1 in Fig. 1B), in their overwound forms (Structure 2 in Fig. 1B) or in their underwound forms (Structure 3 in Fig. 1B). If two 10-base pair arm DNA segments adopt its relaxed form (Structure 1 in Fig. 1B), right-handed orientations of the DNA segments alone will be able to cause generation of negative supercoils in naked linker DNA regions. If two 10-base pair arm DNA segments adopt its overwound form (Structure 2 in Fig. 1B), both right-handed orientations of the DNA segments and overwound structures will cause accumulation of negative supercoils in naked linker DNA regions. If (1) two 10base pair arm DNA segments adopt its underwound form (Structure 3 in Fig. 1B) and (2) effects of right-handed orientation of two 10-base pair arm DNA segments is greater than those produced by underwound form of DNA, negative supercoils will still be produced in naked linker DNA regions.

Discovery 3. In the absence of histone H1, two 10-base pair DNA segments in nucleosomes (1) exist in their arm-closed form if ATP (polyanions) is present and (2) exist in their armopen form if spermidine (polycations) is present. ${ }^{30}$ 
Our recent studies revealed that in the absence of histone H1, ATP as polyanions facilitated two 10-base pair DNA segments to adopt their arm-closed forms in histone H1-free chromatosomes (Fig. 1C). ${ }^{30}$ Different from ATP, spermidine as polycations, however, interacted with negatively charged DNA backbones, ${ }^{40}$ which causes two 10-base pair DNA segments to adopt their arm-open forms in nucleosomes ${ }^{30}$.

Discovery 4. From the quantitative viewpoint, binding of $\sim 11.5$ histone $\mathrm{H} 1$ proteins leads to changes of linking number of -1 in naked linker DNA regions of polynucleosomes, which is equivalent to that binding of one histone $\mathrm{H} 1$ protein to one nucleosome leads to changes of linking number of -0.09 in linker DNA regions of polynucleosomes. ${ }^{31-32}$

Comparison studies of linking number differences between histone-free and histone-bound circular polynucleosomes were conducted by our group previously on the basis of chloroquine-assisted gel electrophoretic analysis. ${ }^{31-32}$ These studies allowed us to quantitatively determine magnitudes of negative DNA supercoils caused by binding of histone $\mathrm{H} 1$ to nucleosomes (Fig. 1D). ${ }^{31-32}$

A.

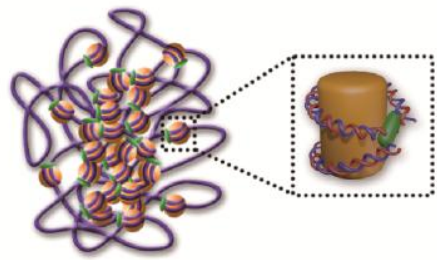

Aggregates of histone H1-plasmidic polynucleosomes

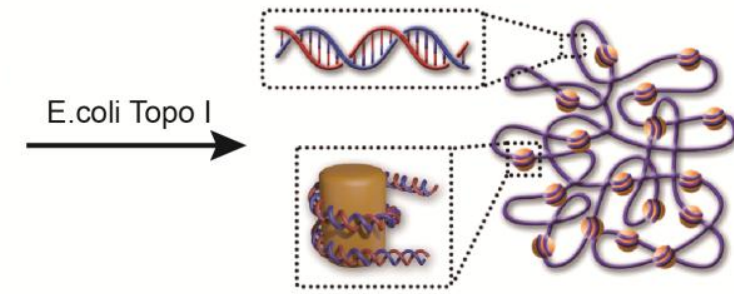

Plasmidic polynucleosomes

B.

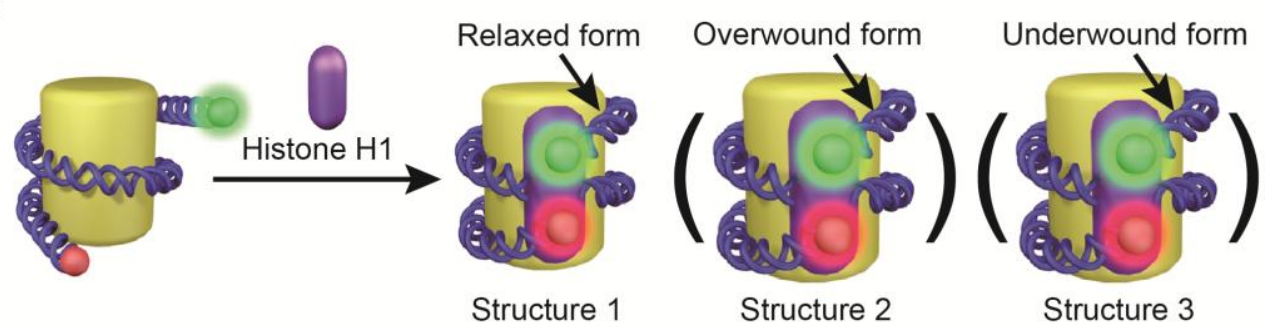

C.

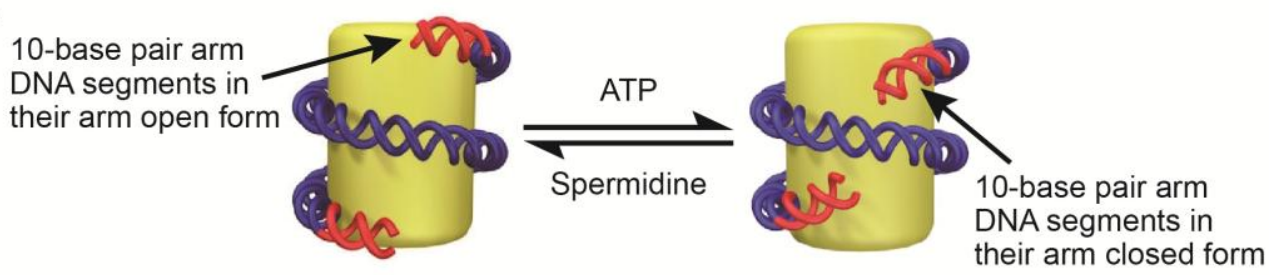

D.

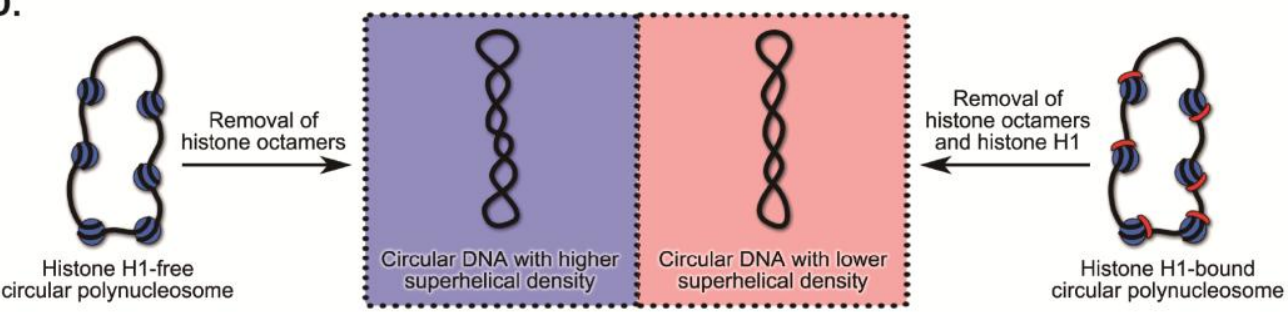

Fig. 1. Pictorial illustration of Discovery 1 (A), Discovery 2 (B), Discovery 3 (C) and Discovery 4 (D) that were made by our group in the recent years. ${ }^{29-32}$ Adapted from (1) 
Bioorganic \& Medicinal Chemistry Letters, 27, Hao Zhang and Tianhu Li, Presence of negative supercoiling in aggregates of histone H1-plasmidic polynucleosome complexes, 168-170, Copyright (2018), (2) Bioorganic \& Medicinal Chemistry Letters, 27, Hao Zhang and Tianhu Li, Effects of spermidine and ATP on stabilities of chromatosomes and histone H1-depleted chromatosomes, 1149-1153, Copyright (2018), and (3) Bioorganic \& Medicinal Chemistry Letters, 28, Hao Zhang and Tianhu Li, Quantitative determination of linking number differences between circular polynucleosomes and histone H1-bound circular polynucleosomes, 537-540, Copyright (2018), with permission from Elsevier.

\subsection{Four axioms about correlations among shapes, signs and handedness of DNA supercoils}

From the supercoiling standpoint, (1) covalently closed circular DNA and (2) linear DNA with non-rotatable terminuses can exist in their (i) underwound form, (ii) overwound forms, and (iii) relaxed forms, whose signs are designated as (i) negative (-), (ii) positive (+), and (iii) zero respectively. ${ }^{1-2}$ Different from relaxed form of DNA, negative and positive DNA supercoils are capable of adopting one of the following four types of shapes: (1) right-handed toroids, (2) left-handed toroids, (3) right-handed plectonemes, and (4) left-handed plectonemes. ${ }^{1-2,33-34}$ Commonly accepted rules about correlations among the aforementioned shapes, signs, and handedness of DNA supercoils can be summarized into four axioms (Table 1) as outlined as follows:

Axiom 1. If sign of a DNA supercoil is negative and it holds a toroidal shape, this DNA toroid is left-handed, and vice versa;

Axiom 2. If sign of a DNA supercoil is negative and it holds a plectonemic shape, this DNA plectoneme is right-handed, and vice versa;

Axiom 3. If sign of a DNA supercoil is positive and it holds a toroidal shape, this DNA toroid is right-handed and, vice versa; and

Axiom 4. If sign of a DNA supercoil is positive and it holds a plectonemic shape, this DNA plectoneme is left-handed, and vice versa.

Table 1. Illustration of commonly accepted rules about correlations among signs, shapes, and handedness of DNA supercoils.

\begin{tabular}{ccccc}
\hline Axioms & $\begin{array}{c}\text { Signs of DNA } \\
\text { supercoils }\end{array}$ & $\begin{array}{c}\text { Shapes of DNA } \\
\text { supercoils }\end{array}$ & $\begin{array}{c}\text { Handedness of } \\
\text { structures of } \\
\text { DNA supercoils }\end{array}$ & $\begin{array}{c}\text { Pictorial illustrations } \\
\text { of DNA supercoils* }\end{array}$ \\
\hline
\end{tabular}

Axiom 1 Negative Toroid Left-handed 
Axiom 2 Negative Plectoneme Right-handed

Axiom 3 Positive Toroid Right-handed

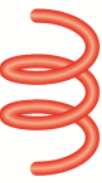

Axiom $4 \quad$ Positive $\quad$ Plectoneme Left handed

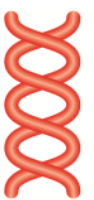

* Single coiled heavy line in these drawings represents backbones of duplex DNA.

\subsection{Our three propositions}

Proposition 1. Genomic DNA macromolecules can be classified into two structural categories: (1) protein-bound DNA and (2) naked linker DNA (protein-free DNA) while (1) naked linker DNA segments are the conformation-alterable elements in chromatins and chromosomes and (2) the ratios of naked linker DNA to protein-bound DNA vary dynamically in chromosomes in eukaryotic cells;

Proposition 2: Three dimensional structures of chromatins and chromosomes at a given instant are govern by (1) superhelical densities of their naked linker DNA segments, (2) backbone rigidness of naked linker DNA segments and (3) abundance and distribution patterns of nucleosome core particles and chromatosomes along their genomic DNA macromolecules; and

Proposition 3: Because conformation-alterable naked linker DNA regions of chromatins and chromosomes are supercoiled, ${ }^{30}$ spatial organizations and handedness of chromosomes and their sublevel architectures can be predicted using the aforementioned four axioms (Section 2.1 and Table 1).

\section{Supercoiling Views of Interphase Chromosomal Structures}

From the standard points of DNA supercoiling and structural organizations, interphase chromosomes can be classified into six hierarchical ranks as depicted in Table 2 and Fig. 2. Because topological properties of double helical structures of DNA (Primary structures) and nucleosomes (Secondary structures) were discussed previously by our group ${ }^{28}$ and others $^{22,35,41-44}$, focus of our discussion in this section of the current report will be on polynucleosomes (Tertiary structures), insulated neighborhoods (Quaternary structures), topologically associating domains (Quinary structures), and interphase chromosomes (Senary structures) respectively. 
Table 2. DNA supercoiling views of hierarchical ranks of structural organizations in interphase chromosomes.

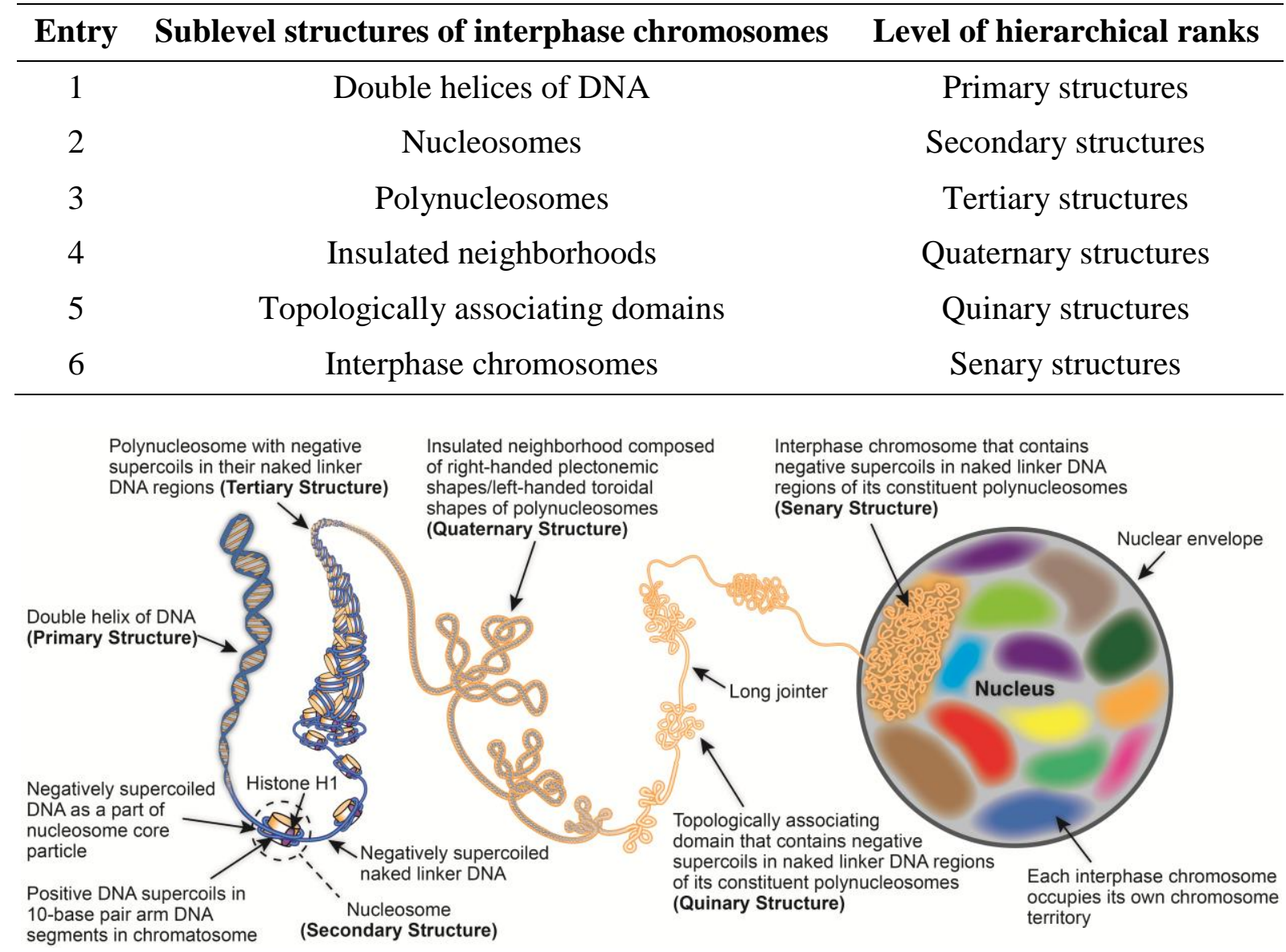

Fig. 2. DNA supercoiling views of spatial organizations of interphase chromosomes and their sublevel architectures.

\subsection{Polynucleosomes as tertiary structures of interphase chromosomes}

A linker DNA is often defined as duplex DNA segments that connect two adjacent nucleosome core particles in polynucleosomes ${ }^{45}$ whereas average length of such DNA segments are $\sim 55$ base pairs ${ }^{46-47}$. On the basis of this aforementioned information ${ }^{45-47}$, (1) densely packed $30 \mathrm{~nm}$ fibers, (2) loosely packed $30 \mathrm{~nm}$ fibers, and (3) slack polynucleosomes are defined in the current report as the polynucleosomal structures that possess their linker DNA segments (1) less than 30 base pairs, (2) around 50 base pairs and (3) longer than 70 base pairs in length respectively (Fig. 3).

(a) Densely packed $30 \mathrm{~nm}$ fibers and loosely packed $30 \mathrm{~nm}$ fibers. Because naked linker DNA segments in $30 \mathrm{~nm}$ fibers are negatively supercoiled (Discovery 1), these negative supercoils will force naked linker DNA segments in $30 \mathrm{~nm}$ fibers to adopt left-handed shapes on the whole once $30 \mathrm{~nm}$ fibers form toroid-like columnar structures (Axiom 1 in Table 1). In addition, because DNA segments in nucleosome core particles are in close physical contact with histone octamers, their conformations are not alterable. Instead, it is the conformationalterable naked linker DNA segments that dominate three-dimensional organizations of nucleosome core particles in $30 \mathrm{~nm}$ fibers (Propositions 2 to 3). Deduction 1 is accordingly 
presented in the current report for describing correlation of overall shapes of naked linker DNA segments with their handedness in $30 \mathrm{~nm}$ fibers.

Deduction 1. Naked linker DNA segments as well as three-dimensional arrangements of nucleosome core particles in densely and loosely packed $30 \mathrm{~nm}$ fibers display left-handed toroidal shapes on the whole (Fig. 3A and Fig. 3B), handedness of which is determined by negative supercoils present in their naked linker DNA regions. In addition, negative DNA supercoils in $30 \mathrm{~nm}$ fibers are irresolvable by topoisomerases in eukaryotic cells because of their (1) low magnitudes of superhelical density, (2) structural compactness and (3) dynamic transitions of 10-base pair arm segments between their arm-open and arm-closed forms.

A.

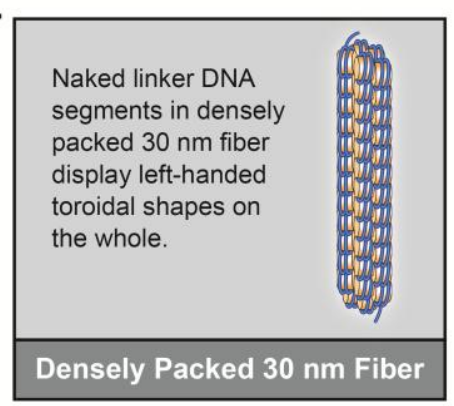

B.

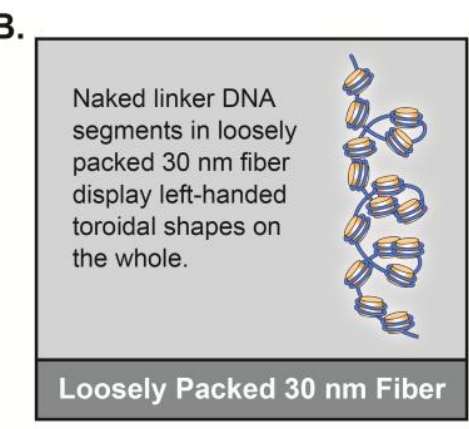

C.

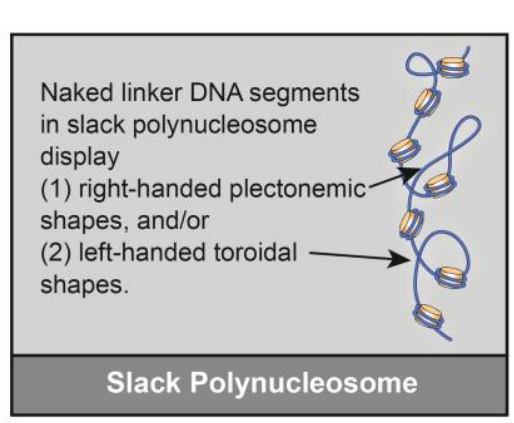

Fig. 3. Pictorial illustration of structures of supercoiling-driven densely packed $30 \mathrm{~nm}$ fibers (A), loosely packed $30 \mathrm{~nm}$ fibers (B) and slack polynucleosomes (C).

Three exquisite models, on the other hand, were introduced in the past for describing spatial packaging patterns of nucleosome core particles in $30 \mathrm{~nm}$ fibers, namely (1) Rhodes one start model $^{48}$, (2) Richmond two start model ${ }^{49}$ and (3) Li and Zhu two start tetra-nucleosomes model $^{50}$ respectively. Even though these three models portray different spatial arrangements of nucleosome core particles, overall stacking patterns of naked linker DNAs in their suggested structures are all left-handed ${ }^{4-50}$ (Fig. 4). This left handedness is coherent with the description specified in Deduction 1.

A.

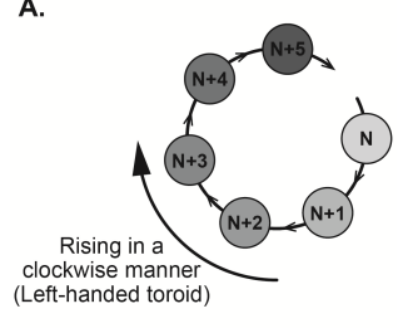

Rhodes one-start model

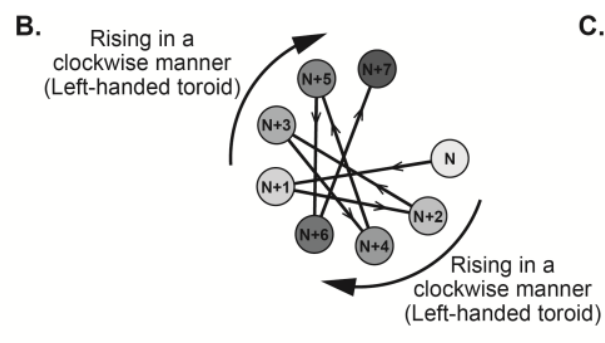

Richmond two-start model

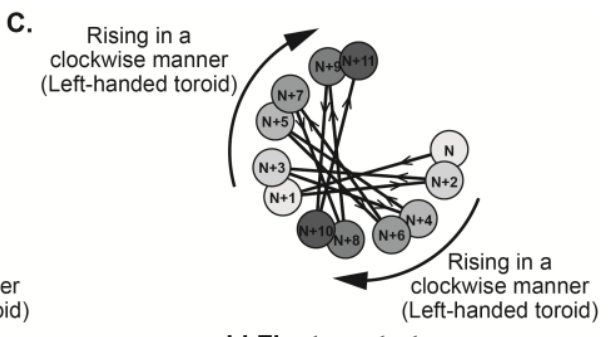

Li-Zhu two-start

tetranucleosome-unit model

Fig. 4. Illustration of left handedness of naked linker DNA segments in Rhodes one-start model $^{48}$ (A), Richmond two-start model ${ }^{49}$ (B), and Li-Zhu two start tetranucleosome-unit $\operatorname{model}^{50}(\mathrm{C})$.

(b) Slack polynucleosomes. Different from (1) densely packed $30 \mathrm{~nm}$ fibers and (2) loosely packed $30 \mathrm{~nm}$ fibers (Fig. 3A and Fig. 3B), slack polynucleosomes as a third form of polynucleosomes possess relatively long naked linker DNA segments between two adjacent 
nucleosome core particles (Fig. 3C). These long linker DNA-holding polynucleosomes are capable of adopting either left-handed toroidal structures or right handed plectonemic structures, which resemble the behaviors of protein-unbound plasmid $\mathrm{DNA}^{51}$. In addition, from the supercoiling viewpoint, magnitudes of superhelical densities of naked linker DNA regions in the abovementioned three types of polynucleosomal structures are in the following order: densely packed $30 \mathrm{~nm}$ fibers > loosely packed $30 \mathrm{~nm}$ fibers > slack poly-nucleosomes. Deduction 2 is accordingly presented in the current report for describing correlations of shapes of slack polynucleosomes with negative DNA supercoils in their naked linker DNA regions:

Deduction 2. Overall backbone structures of slack polynucleosomes as well as their constituent naked linker DNA segments can exist in the shapes of left-handed toroids or right-handed plectonemes (Fig. 3C), which are sustained by negative supercoils present in their naked linker DNA regions.

\subsection{Insulated neighborhood as quaternary structures of interphase chromosomes}

(a) Active, inactive and silent insulated neighborhoods as well as their correlations with plectonemic and toroidal structures of polynucleosomal backbones. An insulated neighborhood refers commonly to a structural assembly of multiple loops of polynucleosomes in interphase chromosomes whose root regions are (1) bound together by CTCF homodimers and (2) co-bound by cohesions ${ }^{52-53}$. It has been estimated that $\sim 13,000$ insulated neighborhoods are present in a eukaryotic cell, each of which contains $\sim 90 \mathrm{kbp}$ in size on average $\mathrm{e}^{52,54}$. From the DNA supercoiling and topological standpoint, overall shapes of insulated neighborhoods are govern by the negative supercoils because (1) negative supercoils are present in naked linker DNA regions of their constituent polynucleosomes and (2) naked linker DNA segments are the only conformation-alterable elements in polynucleosomes. In other words, even though shapes of insulated neighborhoods have been frequently observed under microscopes as multiple irregular loops ${ }^{55-57}$ (Fig. 5A), they are in effect assemblies of supercoiling-driven (1) left-handed plectonemic shapes (Fig. 5B), (2) right-handed toroidal shapes (Fig. 5C) or (3) combination of left-handed plectonemic and right-handed toroidal shapes of polynucleosomes.

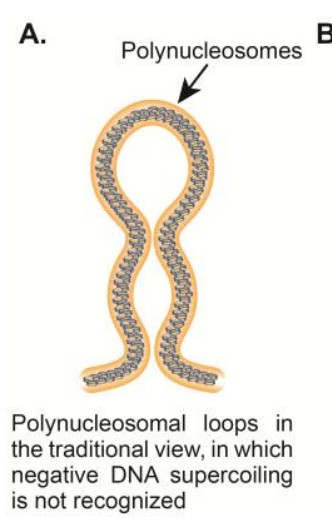

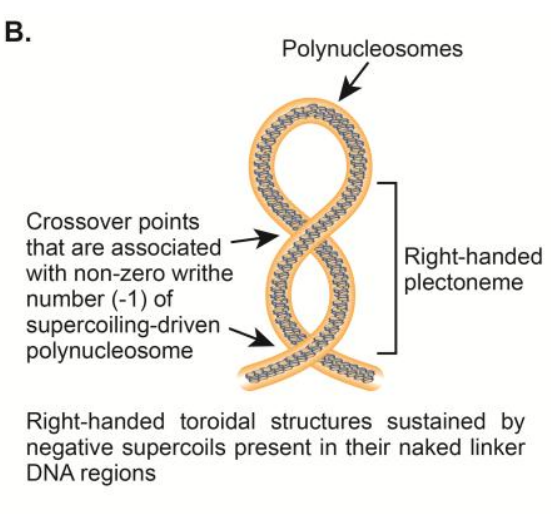

c.

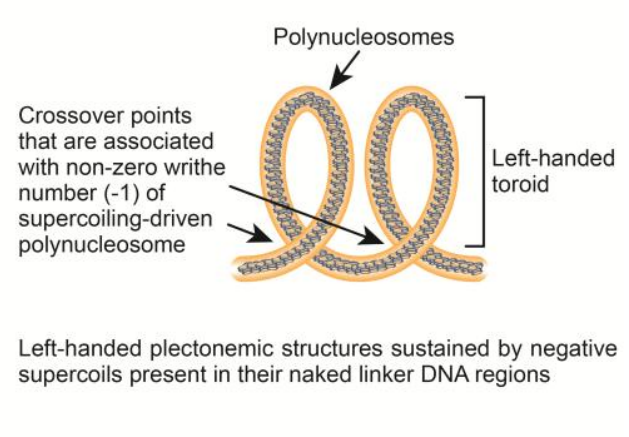

Fig. 5. Illustration of differences between traditional view ${ }^{55-57}$ (A) and supercoiling view (B and $\mathrm{C}$ ) on long spans of backbone structures of polynucleosomes as components of insulated neighborhoods. 
One of the spatial characteristics of supercoil-driven plectonemic and toroidal shapes of DNA, on the other hand, are occurrence of crossover points within their backbone structures, ${ }^{1,38,58}$ which reflects non-zero writhe number as defined in Călugăreanu-White-Fuller Theorem ${ }^{22}$. More specifically, proximities between two pairs of DNA segments (e.g. enhancers and promoters) were often observed experimentally within insulated neighborhoods even though these pairs are in fact separated by up to a million base pairs along their linear polynucleosomal backbones. ${ }^{59-62}$ When viewed from the supercoiling perspective, these proximities between two DNA segments (e.g. two distal enhancers and promoters) are in fact the crossover points of polynucleosomal backbones associated with supercoiling-driven plectonemic and toroidal structures (Fig. 5B and Fig. 5C). Deduction 3 is accordingly presented in the current report for describing correlation of structural characteristics of insulated neighborhoods with negative supercoils in their naked linker DNA regions:

Deduction 3. (1) Insulated neighborhoods are assemblies of (i) left-handed plectonemic shapes (Fig. 5B), (ii) right-handed toroidal shapes (Fig. 5C) or (iii) combination of lefthanded plectonemic shapes and right-handed toroidal shapes of polynucleosomes (Fig. 6), spatial organizations of which are sustained by negative supercoils present in their constituent naked linker DNA segments, and (2) it is the non-zero writhe number-affiliated crossover points of polynucleosomal backbones (Fig. 5B and Fig. 5C) that bring distal DNA segments (e.g. enhancers, silencers, promoters, insulators as well as pairs of CTCF) into proximity in insulated neighborhoods.

In addition, based on their gene expression capacities, insulated neighborhoods can be classified into (1) active insulated neighborhoods, (2) inactive insulated neighborhoods, and (3) silent insulated neighborhoods, which accommodate predominantly (1) active genes, (2) inactive genes and (3) no gene respectively. Active insulated neighborhoods contain mainly loosely packed $30 \mathrm{~nm}$ fibers and slack polynucleosomes (Fig. 6A) while inactive insulated neighborhoods mainly contain tightly and loosely packed insulated neighborhoods (Fig. 6B). Different from active insulated neighborhoods and inactive insulated neighborhoods, silent insulated neighborhoods, however, consist of mostly tightly packed $30 \mathrm{~nm}$ fibers (Fig. 6C). From the supercoiling standpoint, magnitudes of superhelical densities in naked linker DNA regions in the aforementioned three types of structural organizations are in the following order: silent insulated neighborhoods > inactive insulated neighborhoods $>$ active insulated neighborhoods.

A.

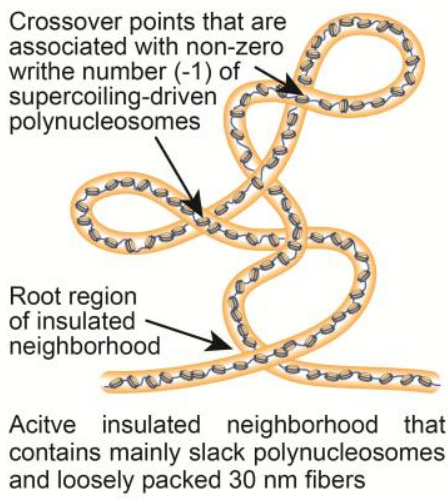

B.

Crossover points that are associated with non-zero writhe number $(-1)$ of supercoiling-driven polynucleosomes

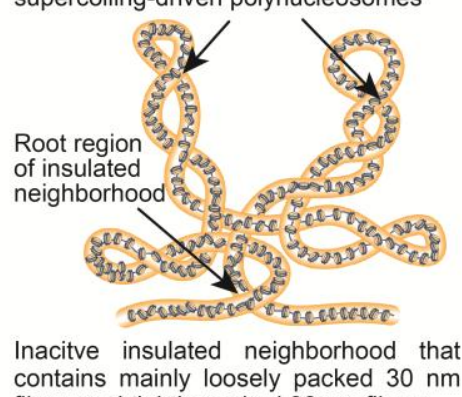

contains mainly loosely packed $30 \mathrm{~nm}$ c.

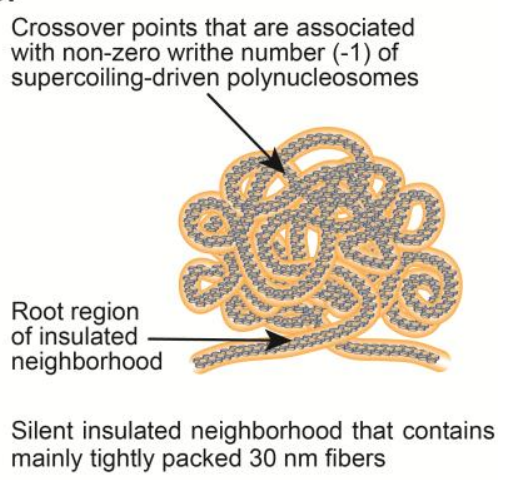


Fig. 6. Illustration of active insulated neighborhoods (A), inactive insulated neighborhoods (B), and silent insulated neighborhoods (C), (i) which are composed of left-handed plectonemes and/or right-handed toroids of polynucleosomes, and (ii) three-dimensional structures of which are sustained by negative supercoils present in their linker DNA regions.

(b) Correlation of regulations of gene expressions with plectonemic and toroidal structures in active insulated neighborhoods. For the convenience of our further discussion, "conformations of polynucleosomes" are defined in the current report as any spatial organizations that polynucleosomes may be able to adopt in an insulated neighborhood. In addition, "stable conformers" are defined as any spatial conformations of polynucleosomal backbones that correspond to local minimal potential energy. Furthermore, "pairable DNA elements" are named as two DNA segments in insulated neighborhoods that are capable of being bound together by protein and other molecules. Examples of such pairable DNA elements are (1) enhancers and promoters, (2) silencers and promoters, (3) insulators and insulators, (4) enhancers and insulators as well as (5) two CTCF DNA sequences ${ }^{61}$. When two pairable DNA segments occur within close ranges at crossover points of supercoilingdriven plectonemic and toroidal structures, they are named "adjacent pairable DNA segments". Once protein and other molecules clasp two adjacent pairable DNA segments together, the resultant plectonemic and toroidal structures in insulated neighborhoods are called "clasped stable conformers" or "clasped conformers". From the viewpoint of supercoiling-driven structures, it is the clasped conformers that determine patterns of gene expressions in insulated neighborhoods (Fig. 7). Deduction 4 is accordingly presented in the current report for describing correlations between regulation of gene expressions and clasped conformers:

Deduction 4. (1) Gene expressions (e.g. facultative and inducible gene expressions) in insulated neighborhoods are permissible if enhancer DNA sequences and promoter DNA sequences occur at crossover points of plectonemes/toroids and are further clasped by DNA binding proteins and other molecules; (2) gene expressions in insulated neighborhoods are suppressed if (i) silencer DNA sequences and gene promoter DNA sequences occur at crossover points of plectonemes/toroids and are further clasped by DNA binding proteins and other molecules, or (ii) either promoter DNA sequences or enhancer DNA sequences do not emerge at crossover points; and (3) when two CTCF DNA sequences occur at the crossover points of plectonemic/toroidal structures and clasped by DNA binding proteins and other molecules, they (i) serve as root regions of insulated neighborhoods or (ii) sustain overall structures of insulated neighborhoods (Fig. 7).

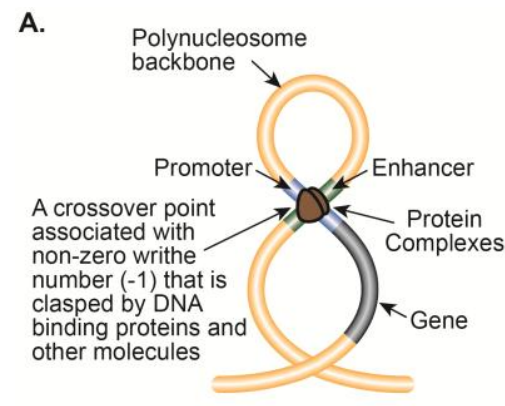

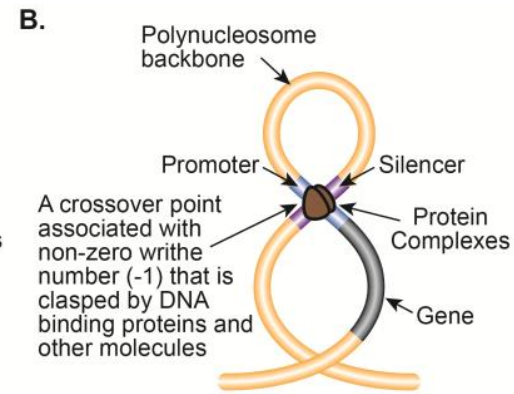

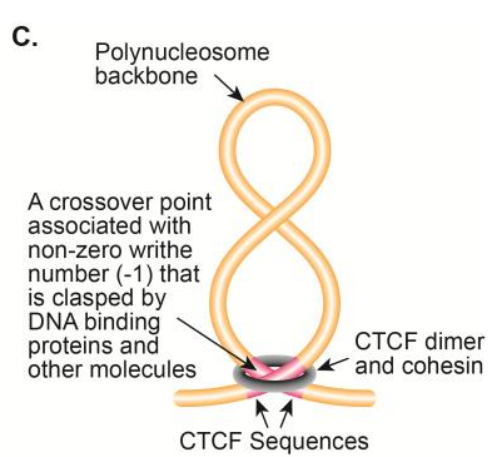


Fig. 7. Illustration of correlations between clasped conformers in insulated neighborhoods and regulations of gene expressions. (A) An enhancer and a promoter are clasped by proteins at a crossover point of supercoiling-driven plectonemes, in which gene expression is permissible, (B) a promoter and a silencer are clasped by proteins at a crossover point of plectonemes, in which gene expression is suppressed, and (C) two CTCF DNA sequences are clasped by proteins at a crossover point of plectonemes, which serves as the root or supporting structural element of an insulated neighborhood.

\subsection{Topologically associating domains as quinary structures of interphase chromosomes}

(a) Active, inactive and silent topologically associating domains. A topologically associating domain is a genomic region in interphase chromosomes, within which DNA sequences physically interact with each other more frequently than those beyond itself. ${ }^{63-64}$ Based on their gene expression capacity and structural denseness, these self-interacting domains can be further classified into (1) active topologically associating domains, (2) inactive topologically associating domains, and (3) silent topologically associating domains, which contain mainly (1) active insulated neighborhoods, (2) inactive insulated neighborhoods, and (3) silent insulated neighborhoods respectively (Fig. 8). In addition, from the supercoiling standpoint, magnitudes of superhelical densities in naked linker DNA regions in these three types of topologically domains are in the following order: silent topologically associating domains > inactive topologically associating domains > active topologically associating domains.

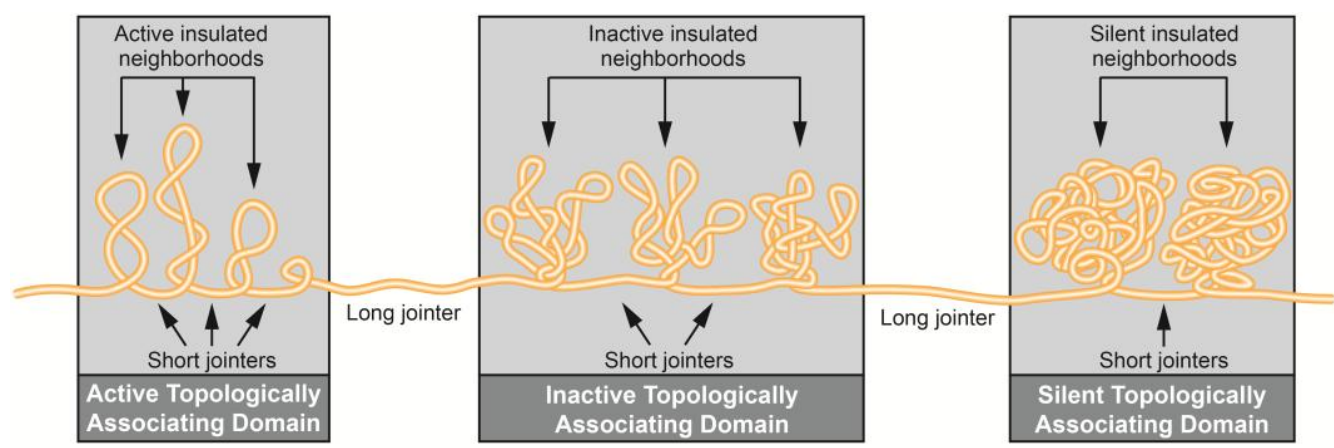

Fig. 8. Illustration of structures of three types of topologically associating domains, which contain mainly (i) active insulated neighborhoods, (ii) inactive insulated neighborhoods, and (iii) silent insulated neighborhoods respectively.

(b) Jointer sequences. The term jointer sequence is defined in the current report as DNA sequences that reside (1) between two insulated neighborhoods and (2) between two topologically associating domains in interphase chromosomes (Fig. 8). Within a topologically associating domain, jointer sequences between two adjacent insulated neighborhoods are comparably short, which are named "short jointers" (Fig. 8). These short lengths of jointers allow negative DNA supercoils to be spread out among adjacent insulated neighborhoods, which in turn makes a topologically associating domain act a self-interacting entity. Conversely, the jointer sequences between two topologically associating domains are relatively longer, which are named "long jointers" in the current report. These longer jointers will prevent propagation of negative DNA supercoils from spreading out of each individual 
topologically associating domain owing to their extended lengths. In addition, since a long jointer region does not contain abundant nucleosome structures, this region could be one of the preferable places for constitutive gene to reside in. ${ }^{65}$ Deduction 5 is accordingly presented below for describing correlations of characteristics of topologically associating domains with negative supercoils in naked linker DNA regions of their constituent polynucleosomes:

Deduction 5. It is the (1) negative supercoils in linker DNA regions of polynucleosomes and (2) short lengths of jointer sequences between insulated neighborhoods that drive each topologically associating domain to act as a self-gathering and self-interacting structural entity (Fig. 8).

(c) Correlation of transposition of transposons and viral insertion with sizes and shapes of insulated neighborhoods and topologically associating domains. Mobile genetic elements are DNA sequences that are capable of relocating or can be copied from one location to another in organismal genomes. ${ }^{66}$ In eukaryotic cells, these mobile genetic elements are mainly transposons (transposable elements), which include retrotransposons and DNA transposons. ${ }^{66-67}$ Similar to transposons, virus, on the other hand, is capable of increasing spans of DNA sequences as well through its insertion actions. ${ }^{68-70}$ From DNA supercoiling standpoint, transposition of mobile genetic elements and viral insertion could lead to alteration of (i) shapes, (ii) crossover points of polynucleosome backbones and (iii) sizes of insulated neighborhoods and topologically associating domains (Fig. 9 and Fig. 10). Deduction 6 is accordingly presented in the current report for describing consequence of transposition of mobile genetic elements and insertion of virus on plectonemic and toroidal structures of polynucleosomes:

Deduction 6. Transposition of transposons and viral insertion (1) are capable of altering shapes, crossover points of polynucleosome backbones and sizes and boundaries of insulated neighborhoods and topologically associating domains, which could in turn change original relative positions of pairable DNA elements and affect patterns of gene expressions in the neighborhoods and domains (Fig. 9 and Fig. 10), and (2) can position the DNA sequences of promoters, enhancers, silencers and CTCF that transposons and viruses carry at crossover points or away from crossover points of polynucleosome backbones in insulated neighborhoods and topologically associating domains.

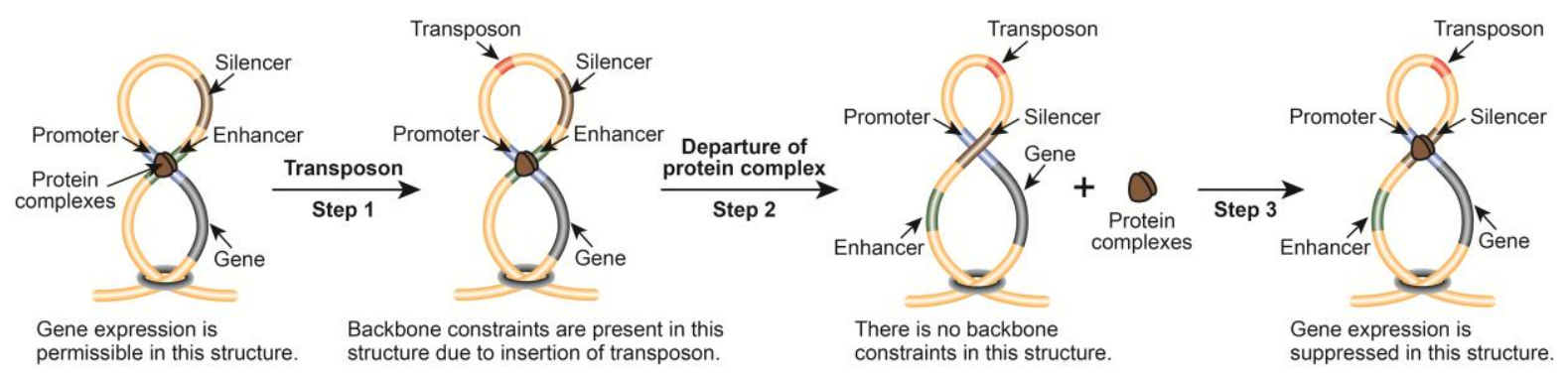

Fig. 9. Illustration of actions of transposons on gene expressions within an insulated neighborhood. Step 1: Insertion of a transposon that leads to generation of backbone constraints in clasped polynucleosomal structures; Step 2: departure of DNA binding protein complexes that leads to release of backbone constraints; and Step 3: association of complexes that re-clasps newly established stable conformer. 
A.

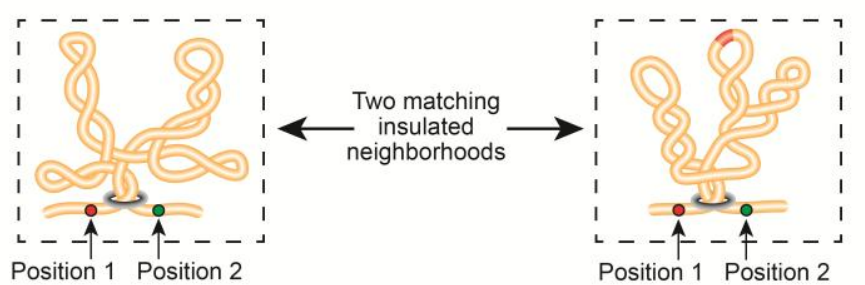

B.

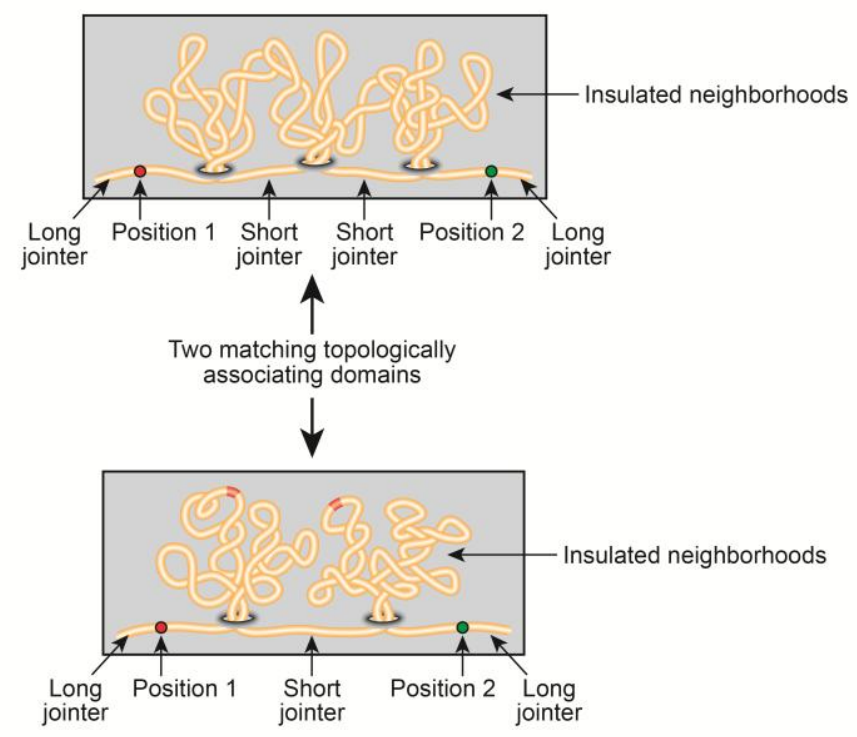

C.

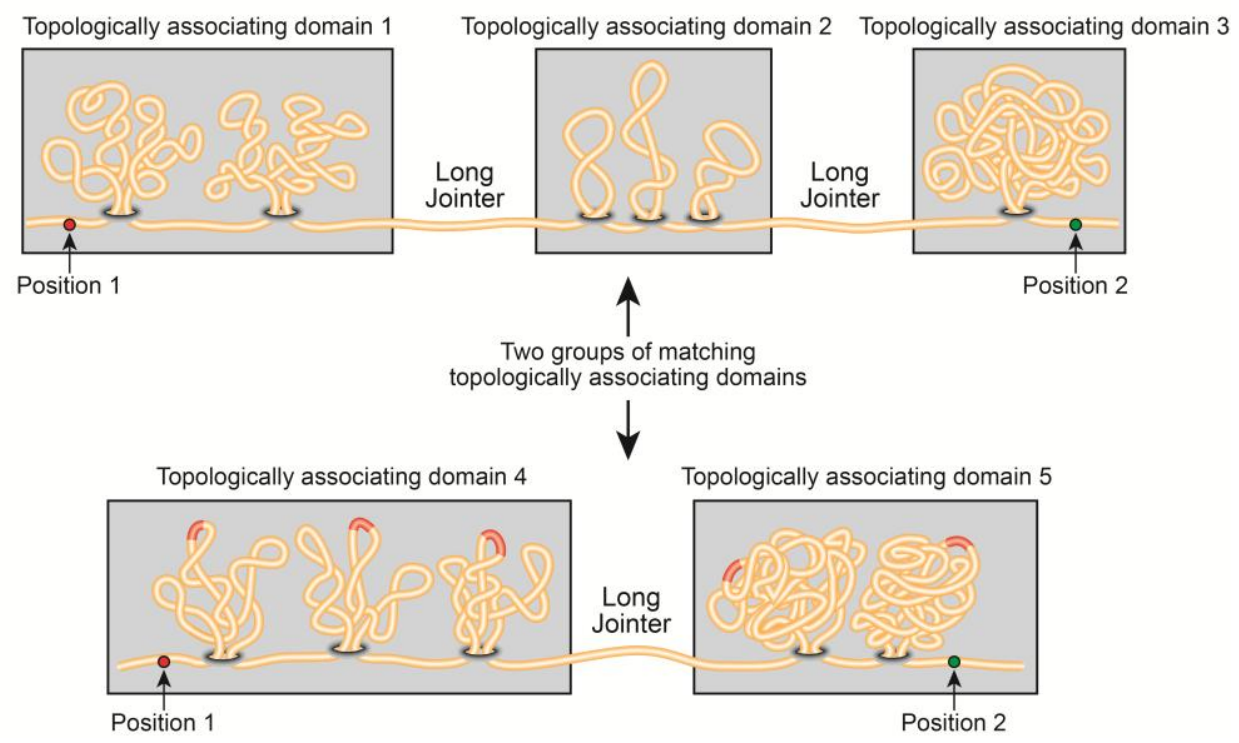

Fig. 10. Illustration of transpositions of transposon-caused changes of matching insulated neighborhoods/topologically associating domains. (A) Alteration of shapes of matching insulated neighborhoods without changes in root regions. (B) (i) Alteration of sizes of matching insulated neighborhoods and (ii) alteration of shapes of two matching topologically associating domains without changes of boundaries of the domains. (C) Alterations of size and shape of matching topologically associating domains.

(d) Correlations of supercoiling-driven insulated neighborhoods/topologically associating domains with (1) cell types, (2) genetic density, (3) diverse variants of polynucleosomal structures in cells in the same brain and (4) adaptive roles of transposable elements. For 
the convenience of our further discussions, matching insulated neighborhoods and matching topologically associating domains are defined in the current report as the insulated neighborhoods and topologically associating domains that occur at the same loci of homologous chromosomes (1) in different or identical cell types, or (2) in the cells of organisms of the same species.

(1) Cell types. An individual cell in a multicellular organism possesses an identical set of genomic DNA to that of every other cell in the organism. ${ }^{71}$ In spite of this genetic equality, a multicellular organism possesses various specialized cell types (e.g. liver cells and lung cells in human) for their diverse cellular functions. ${ }^{71}$ It has been commonly acceptable nowadays that distinct patterns of gene expressions make genetically identical cells turn out to be different cell types. ${ }^{72-73}$ Transposition of transposons ${ }^{66}$ and viral insertions ${ }^{68}$, on the other hand, are capable of altering shapes and sizes of supercoiling-driven insulated neighborhoods and topologically associating domains as well as crossover points of their constituent polynucleosomes (Deduction 6). From the DNA supercoiling viewpoint, it is the differences of crossover points of plectonemic and toroidal structures caused by activity of transposons in matching insulated neighborhoods/topologically associating domains that lead to different profiles of gene expressions in different cell types.

(2) Genetic diversity. Variations of alleles are present in chromosomes within a species population, number of which is often used as a measure of genetic diversity. ${ }^{74-75}$ From the DNA supercoiling standpoint, one of the main structural bases of such variations in alleles and genetic diversity is that shapes and sizes of matching insulated neighborhoods/topologically associating domains as well as positions of crossover points at the same loci on chromosomes in individuals of identical species are different while such differences can be resulted from actions of transpositions of transposons and/or insertion of virus.

(3) Wide-ranging variants of genomic structures in cells in the same brain. It has been known that unlike those in any other organs of human body, cells in the same brain are widely different from one another in their genomic structures ${ }^{76}$ From the DNA supercoiling viewpoint, a single action of transposon could cause drastical structural changes of an entire insulated neighborhood and an entire topologically associating domain (Fig. 9 and Fig. 10). Therefore, it is the (1) high structural vulnerability of supercoiling-driven insulated neighborhoods and topologically associating domains to actions of transposons and (2) exceptional high activity of transposons in brain cells ${ }^{76}$ that is accountable for emergence of wide-ranging variants of genomic structures in cells in the same brain.

(4) Adaptive transposable elements. It has been known that adaptive transposable elements are widespread in nature and their transpositions enable organisms to adapt gene expression to environmental changes. ${ }^{77-79}$ Because actions of transposable elements are able to alter shapes and sizes of DNA supercoiling-driven insulated neighborhoods and topologically associating domains, these structural alterations could (1) introduce new adjacent pairable elements to insulated neighborhoods and topologically associating domains as well as (2) alter the distances between preceding adjacent pairable elements. It is therefore anticipated 
that transposon-affiliated structural changes of insulated neighborhoods and topologically associating domains are accountable for the fundamental mechanisms that underlie transposable element-induced adaptation ${ }^{78-79}$ in organisms.

In view that spatial structures of supercoiling-driven insulated neighborhoods and topologically associating domains are highly susceptible to length changes of their constituent DNA, Deduction 7 is accordingly presented in the current report for describing consequences of activity of transposons and viral insertions on properties of eukaryotic cells:

Deduction 7. Transposition of transposon alone, virus insertion alone or combination of the aforementioned two types of actions are capable of leading to differences in (1) shapes and sizes between matching insulated neighborhoods and matching topologically associating domains, as well as (2) relative spatial positions of pairable elements, which are accountable for (i) different gene expression profiles by different cell types, (ii) genetic diversity of a species' population, (iii) wide-ranging variants of genomic structures in cells in the same brains, and (iv) implementation of adaptable roles of transposable elements in organisms (Fig. 9 and Fig. 10).

\subsection{Overall spatial organizations of interphase chromosomes as their own senary structures}

It has been known that (1) interphase chromosomes in nuclei of eukaryotic cells display nearly spheroidic shapes on the whole ${ }^{80}$, and (2) individual chromosomes perform their cellular actions in their own chromosome territories ${ }^{81-83}$. From the DNA supercoiling standpoint, these self-cohesive behaviors of interphase chromosomes are caused by immense accumulation of negative supercoil-affiliated backbone curvatures in their naked linker DNA regions (Fig. 2). In addition, on the basis of their interactions with membrane structures, interphase chromosomes can be classified into (1) lamina-associated domains ${ }^{84}$, (2) nucleolus-associated domains ${ }^{85-86}$, and (3) non-membrane-associated domains. Laminaassociated domains and nucleolus-associated domains bind to inner membrane of the nucleus and surround highly transcribed region of nucleolus respectively, and are structurally composed of silent and inactive topologically associating domains. Non-membraneassociated domains, on the other hand, are defined in the current report as polynucleosomal structures that are free from binding to lamina and nucleolus. When viewed from the DNA supercoiling perspective, magnitudes of superhelical densities of the aforementioned three types of domains are in the following order: lamina-associated domains = nucleolusassociated domains > non-membrane-associated domains. Deduction 8 is accordingly presented in the current report for describing correlation of structural characteristics of interphase chromosomes with negative supercoils present in their naked linker DNA regions:

Deduction 8: Centripetal and elastic characteristics of overall structures of interphase chromosomes in eukaryotic cells are determined by negative supercoil-enforced backbone curvatures in naked linker DNA regions of their constituent polynucleosomes, which drives each interphase chromosome to stay in its own chromosome territory in a eukaryotic nucleus (Fig. 2). 


\section{Supercoiling Views of Chromosomal Structures in Mitotic Phase and Meiotic Phase of Cell Divisions}

Chromosomes in mitotic phase and meiotic phase of eukaryotic cells are highly condensed structural entities of nucleic acids and proteins, in which compactions of DNA could be up to $\sim 250$-fold higher than those in interphase chromosomes. ${ }^{87-88}$ Based on their supercoiling and structural characteristics, these mitotic phase and meiotic phase chromosomal structures can be further classified into six hierarchical ranks as depicted in Table 3 and Fig. 11. Because (1) topological features of double helical structures of DNA (Primary structures as listed in Table 3) were reviewed previously ${ }^{2,22,41}$ and (2) supercoiling properties of nucleosomes and polynucleosomes (Secondary and Tertiary structures as listed in Table 3) were discussed in Section 2.1 and Section 3.1 in the current report, focus of our discussions in the current section will be on (1) plectoroids (Quaternary structures), (2) left-handed helical polyplectoroids (Quinary structures), and (3) bivalent chromosomes (Senary structures) respectively.

Table 3. DNA supercoiling views of hierarchical ranks of structural organizations of chromosomes in mitotic phase and meiotic phase.

\begin{tabular}{ccc}
\hline Entry & $\begin{array}{c}\text { Sublevel architectures of mitotic } \\
\text { phase and meiotic chromosomes }\end{array}$ & $\begin{array}{c}\text { Hierarchical ranks of architectures in } \\
\text { mitotic phase and meiotic chromosomes }\end{array}$ \\
\hline 1 & Double helical DNA & Primary structures \\
2 & Nucleosomes & Secondary structures \\
3 & Polynucleosomes & Tertiary structures \\
4 & Plectoroids (Loop domains) & Quaternary structures \\
5 & Left-handed helical polyplectoroids & Quinary structures \\
6 & Bivalents & Senary structures \\
\hline
\end{tabular}




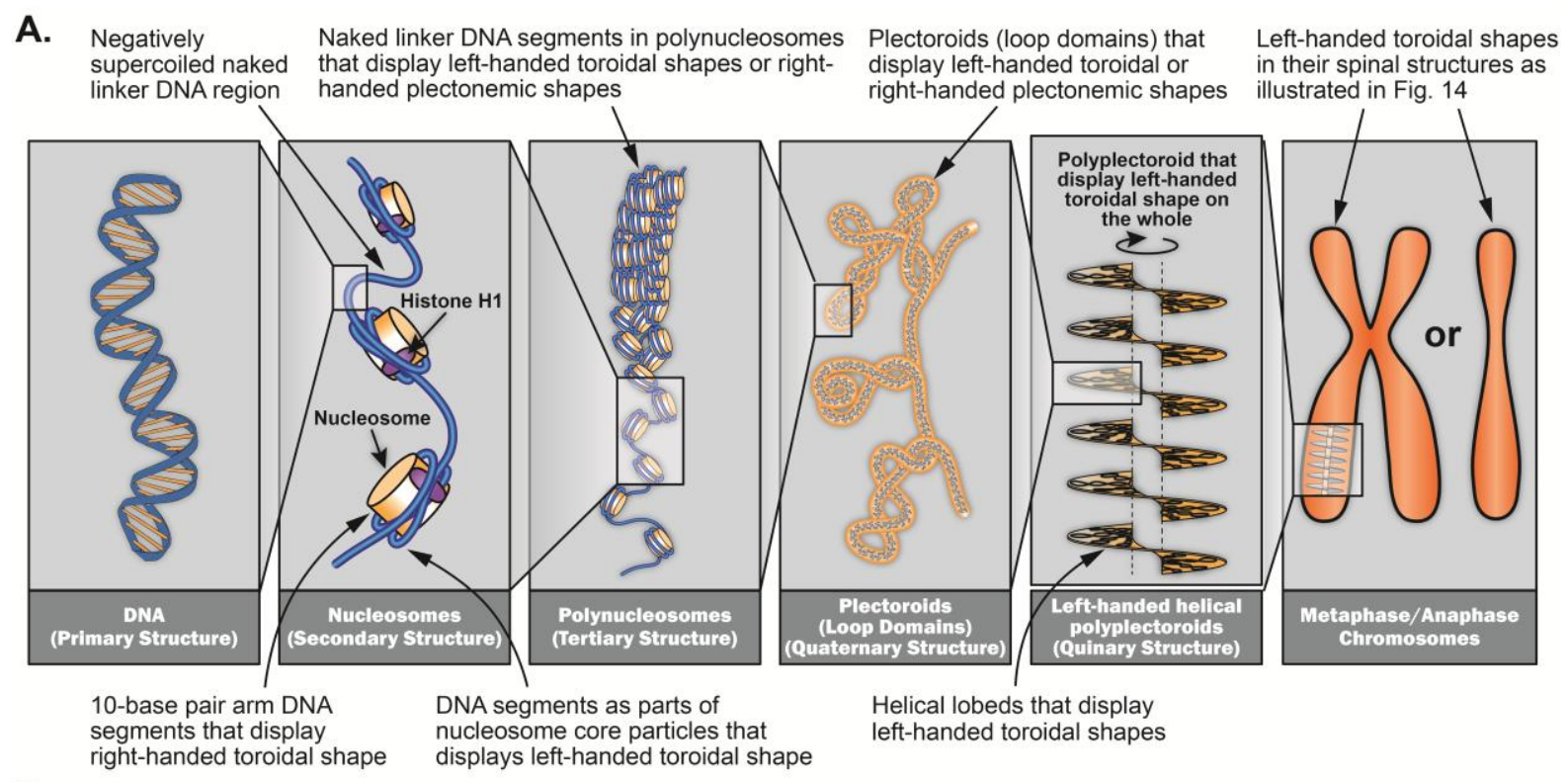

B.

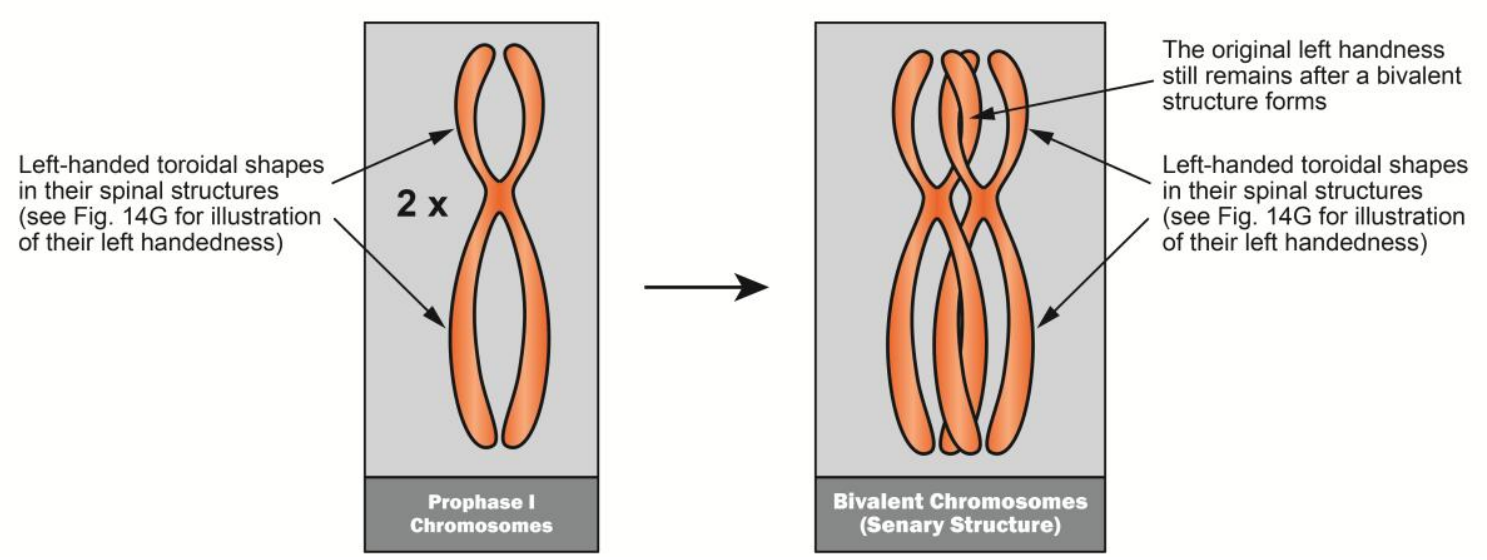

Fig. 11. Supercoiling models of hierarchical architectures of metaphase and anaphase chromosomes in mitosis and meiosis (A), and in meiotic synapsis in Prophase I (B).

\subsection{Plectoroids ("Loop domains") as quaternary structures of metaphase chromosomes}

The term "loop domain" has been used in the past for describing a spatial organization of metaphase chromosomes that is one hierarchical level higher than $30 \mathrm{~nm}$ fibers. ${ }^{89-90}$ When viewed from the DNA supercoiling perspective, loop domains are in fact closely correlated with insulated neighborhoods even though these two terms have been used for portraying substructural organizations of chromosomes in metaphase and interphase in cell division cycles separately ${ }^{53,89-92}$. In other words, both loop domains and insulated neighborhoods are assemblies of supercoiling-driven polynucleosomal structures (Fig. 12), whose root regions are clasped by CTCF homodimers and cohesins while structural denseness and superhelical densities in these two types of structures are different. In addition, similar to insulated neighborhoods, loop domains are not simply loop-like structures as they were portrayed in the past. ${ }^{89-90}$ From the DNA supercoiling standpoint, they are (1) left-handed toroidal shapes, (2) right-handed plectonemic shapes and/or (3) combination of left-handed toroidal shapes and right-handed plectonemic shapes of polynucleosomes. In order to accurately describe quaternary structures of chromosomes in prophase, metaphase, anaphase and telophase, the 
word "plectoroid" (Fig. 11) as a combination of two words, plectoneme and toroid, is suggested in the current report for replacing the term "loop domain". Deduction 9 is consequently presented in the current report for describing correlation of insulated neighborhoods with plectoroids in eukaryotic cells:

Deduction 9: Insulated neighborhoods and plectoroids (loop domains) are the basic functional units in interphase chromosomes and mitotic/meiotic phase chromosomes respectively, both of which are assemblies of supercoiling-driven polynucleosomes. Insulated neighborhoods of interphase chromosomes will turn into plectoroids (loop domains) of prophase and metaphase chromosomes, and plectoroids (loop domains) in anaphase and telophase chromosomes will become insulated neighborhoods in interphase chromosomes in cell division cycles whereas such conversions are affiliated with superhelical densities change of naked linker DNA segments in their constituent polynucleosomes as well as their association/dissociation of proteins and other molecules.

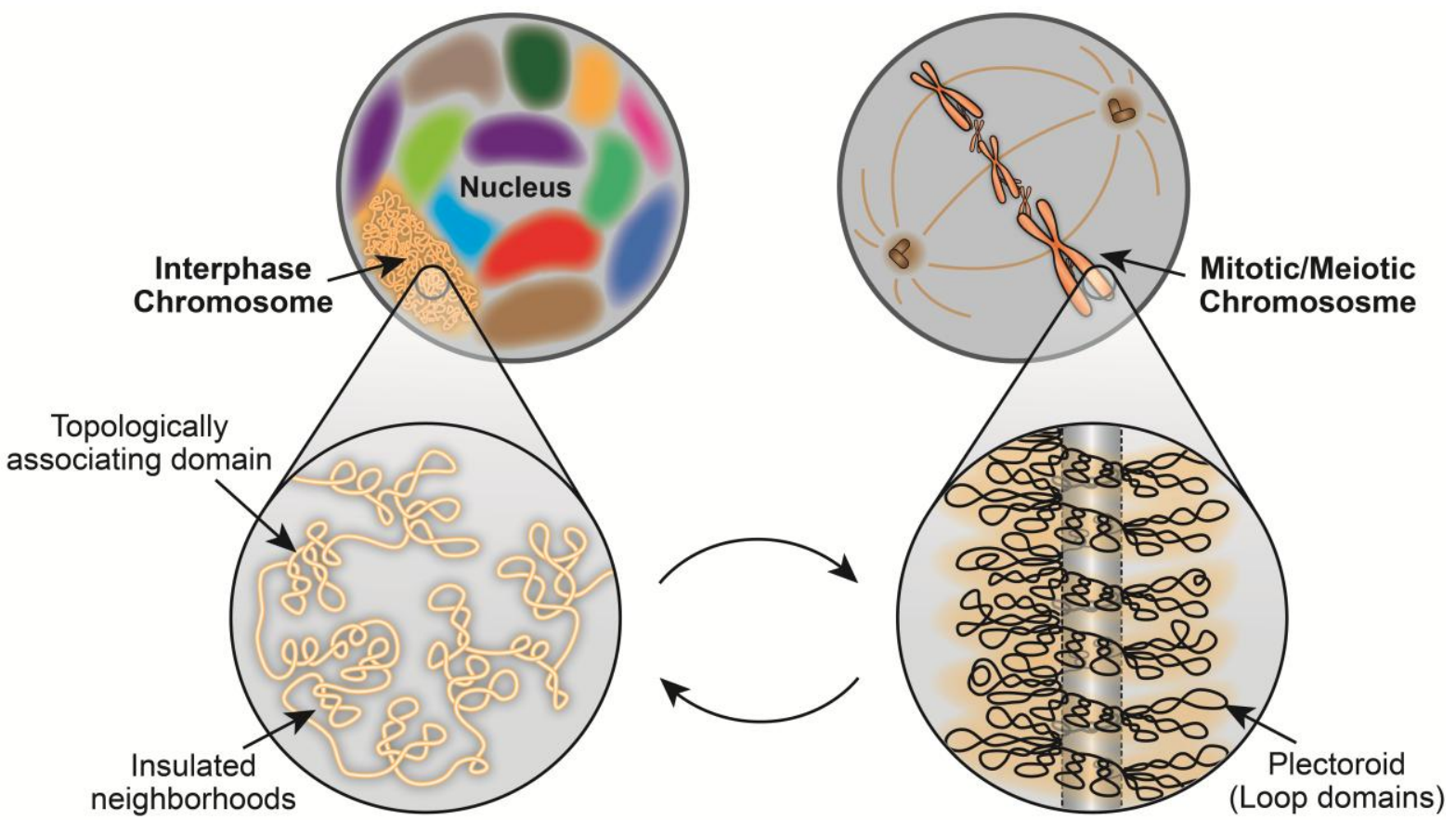

Fig. 12. Illustration of correlations of insulated neighborhoods of interphase chromosomes with plectoroids (loop domains) of mitotic/meiotic phase chromosomes.

\subsection{Left-handed helical polyplectoroids as quinary structures of mitotic/meiotic phase chromosomes}

The term "left handed helical polyplectoroid" is designed in the current report for describing bulky stacks of supercoiling-driven plectoroids, which is the quinary structure of mitotic/meiotic phase chromosomes. Based on their overall spatial denseness and pairing relationship, these left-handed structural entities can be categorized into (1) loose left-handed helical polyplectoroids, (2) interconnected loose left-handed helical polyplectoroids, (3) compact left-handed helical polyplectoroids, and (4) interconnected compact left-handed helical polyplectoroids respectively. 
(a) Loose left-handed helical polyplectoroids and interconnected loose left-handed helical polyplectoroids. Loose left-handed helical polyplectoroids (Fig. 14G) and interconnected loose left-handed helical polyplectoroids (Fig. 14A) are the forms of chromosomes that occur in prophase and telophase in cell division cycles in mitosis and meiosis respectively. Within these chromosomal structures in prophase and telophase (Fig. 14G and Fig. 14A), root regions of polyplectoroids form helical structures while the rest portions of polyplectoroids are oriented upward, downward and straight outward respectively (Fig. 13A). The overall shapes and left handedness of these polyplectoroids are determined by negative supercoils in their naked DNA regions, which are affiliated with (1) equilibrium between their arm-open and arm-close forms of 10-base pair arm DNA segments in the absence of histone H1 (Discovery 3) and (2) histone H1-enforced formation of arm-close forms (Discovery 2) respectively. Because (1) these loose helical polyplectoroids display toroid-like structures on the whole, and (2) sign of supercoils in their naked linker DNA regions is negative (-), these toroidal structures are left-handed (Axiom 1). Deduction 10 is accordingly formulated in the current report for describing correlation of handedness of loose helical polyplectoroids with negative supercoils present in their naked linker DNA regions:

Deduction 10. Prophase chromosomes (Fig. 14A) and telophase chromosomes (Fig. 14G) adopt the structures of loose left-handed helical polyplectoroids and interconnected loose left-handed helical polyplectoroids (Fig. 13A), which are sustained by negative supercoils present in naked linker DNA regions of their constituent polynucleosomes. The negative supercoils in these loose helical polyplectoroids are produced mainly by binding of 10-base pair arm DNA to histone octamers (Discovery 2 and Discovery 3 as illustrated in Fig. 1B and Fig. 1C), which cannot be relaxed by topoisomerases owing to their (1) low magnitudes of superhelical density, (2) structural compactness and (3) dynamic transitions of 10-base pair arm segments between their arm-open and arm-closed forms.

A.

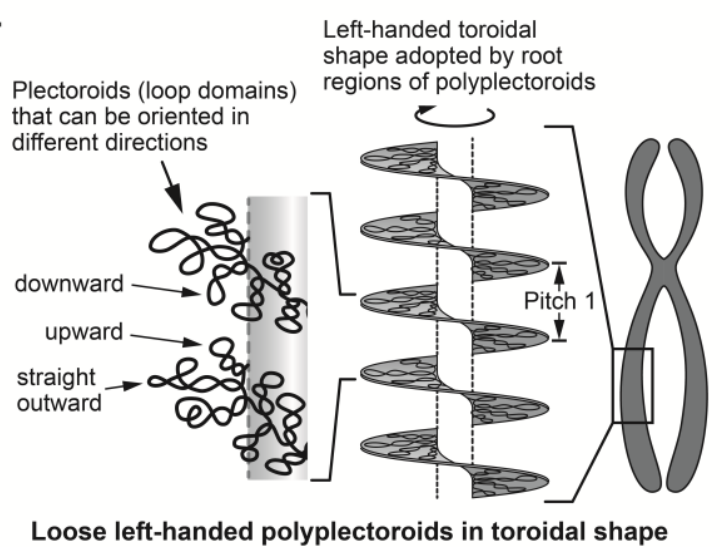

B.

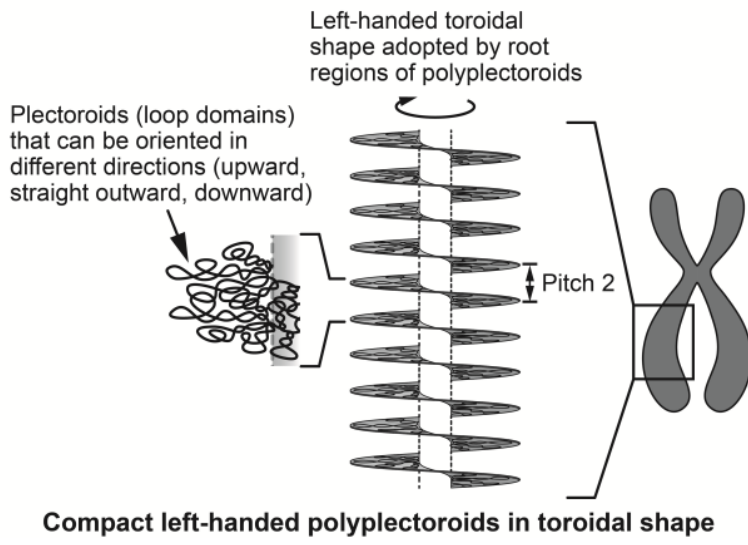

Fig. 13. Illustration of spatial structures of loose left-handed helical polyplectoroids/interconnected loose left-handed helical polyplectoroids (A), and compact left-handed helical polyplectoroids/ interconnected compact helical polyplectoroids (B).

(b) Compact left-handed helical polyplectoroids and interconnected compact left-handed helical polyplectoroids. At the end of prophase of mitosis and prophase I of meiosis, nuclear envelope is broken down, ${ }^{93}$ which allows cytoplasmic condensin I to interact with 
interconnected loose helical polyplectoroids (prophase chromosomes) (Fig. 13A) to form interconnected compact left-handed plectoroids (metaphase chromosomes) (Fig. 13B and Fig. 13E). Condensin $\mathrm{I}$ is a protein complex that generates positive supercoils in the DNA segment that it binds to. ${ }^{94-95}$ From the DNA supercoiling viewpoint, negative supercoils must be produced simultaneously in its adjacent DNA regions in order to compensate positive supercoils of DNA segments that are in close contact with condensin I. In addition, because condensin I is a highly abundant chromosome-associated protein in metaphase ${ }^{96}$, remarkably high negative superhelical densities should be generated in the naked linker DNA regions of entire chromosomes at this stage. These condensin I-affiliated high negative superhelical densities in linker DNA regions along with (1) pre-existing 10 base pair arm DNA-affiliated negative supercoiling (Discovery 1 and Discovery 2) as well as (2) actions of cohesions, topoisomerase II, histone H1, condensin II and other related proteins ${ }^{36,97-100}$ lead to extraordinarily high denseness of interconnected compact left-handed helical polyplectoroids (metaphase chromosomes) and compact left-handed helical polyplectoroids (anaphase chromosomes) (Fig. 13B, Fig. 14B and Fig. 14F). In addition, magnitude of vertical distance between one consecutive helical turn in compact left-handed polyplectoroids (Pitch 1 in Fig. $13 \mathrm{~A}$ ) is greater than that of loose left-handed polyplectoroids (Pitch 2 in Fig. 13B). Deduction 11 is accordingly presented in the current report for describing correlation of high denseness of compact helical polyplectoroids with negative supercoils in naked linker DNA regions of their constituent polynucleosomes:

Deduction 11. Binding of Condensin I to DNA macromolecules will cause tremendous enhancement of magnitudes of negative superhelical densities in naked linker DNA regions, which cannot be relaxed by topoisomerases owing to (1) high structural compactness of chromosomes and (2) short lengths of naked linker DNA segments at this stage.

Deduction 12. Interconnected compact left-handed helical polyplectoroids (metaphase chromosomes) (Fig. 14B) possess remarkable high negative superhelical densities in their naked linker DNA regions, which (1) are produced (i) by binding of Condensin I to DNA macromolecules (Deduction 11), and (ii) by binding of 10-base pair arm DNA segments to histone octamers (Discovery 2 and Discovery 3 as illustrated in Fig. 1B and Fig. 1C). These high negative superhelical densities in naked linker DNA regions at this stage along with binding actions of cohesions, topoisomerase II, histone H1, condensins and other molecules are accountable for extraordinarily high structural compactness of metaphase chromosomes (Fig. 14B) and anaphase chromosomes (Fig. 14 F).

\subsection{Bivalents as senary structures of chromosomes that emerge in prophase $I$ of meiosis}

(a) Loose bivalent structures. From the supercoiling standpoint, even though they were often portrayed as long column-like entities in the past ${ }^{71}$, the spines of (1) chromosomal structures in telophase and (2) each chromatid within homologous chromosomes in prophase do not display uniform columnar shape. Instead, they display the features of left-handed toroids along their spinal columns (Fig. 14F and Fig. 14 G) because negative supercoils are present in naked linker regions of their constituent polynucleosomes (Axiom 1). Bivalents, on the 
other hand, are spatial organizations of two pairs of homologous chromosomes that are formed prior to chromosomal crossover in prophase I of synapses in meiosis. ${ }^{71,101}$ The bivalent structures formed at this stage are defined in the current report as loose bivalents (Fig. 14C) in reference to the bivalent structures formed in metaphase I in meiosis, which are named compact bivalents ${ }^{102}$ (Fig. 14D). Within a loose bivalent structure, two chromatids from each of the two homologous pairs of chromosomes are held together in the forms of synaptonemal complexes. ${ }^{103}$ As a result, each of the two chromatids in the mutually bound portions of loose bivalents remain their left-handed toroidal shapes (Fig. 14C).

(b) Compact bivalent structures (Fig. 14 D). After chromosomal crossover completes and before metaphase I starts, a bivalent structure still displays its left-handed loose form (Fig. 14 C). Once nuclear envelope is disintegrated at the beginning of metaphase I, cytoplasmic condensin I along with other pre-existing molecules (e.g. condensin II and cohesin) convert prophase I loose bivalent structures into metaphase I compact bivalents (Fig. 14E). Owing to the presence of negative supercoils in their constituent DNA regions, spinal columns of metaphase I compact bivalent structures still remain their left-handed toroidal shapes even though the overall length of columnar structures of chromatids become shorter at this stage. Deduction 13 is accordingly presented in the current report for describing alignments of two pairs of homologous chromosomes in bivalent structures:

Deduction 13. Within a loose bivalent structure, sister chromatids wind around each other and hold left-handed toroidal shapes along their spinal columns (Fig. 14C) whereas this left handedness still remains when loose bivalent structures are converted into compact bivalent structures (Fig. 14 D and Fig. 14 E) upon broken down of nuclear envelops.

A.

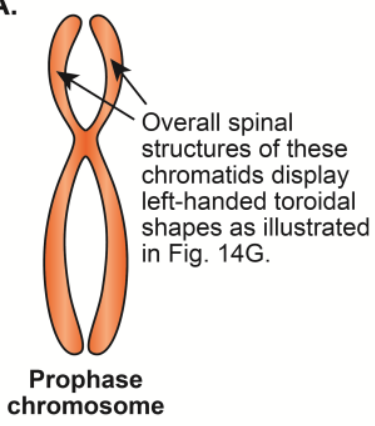

E.

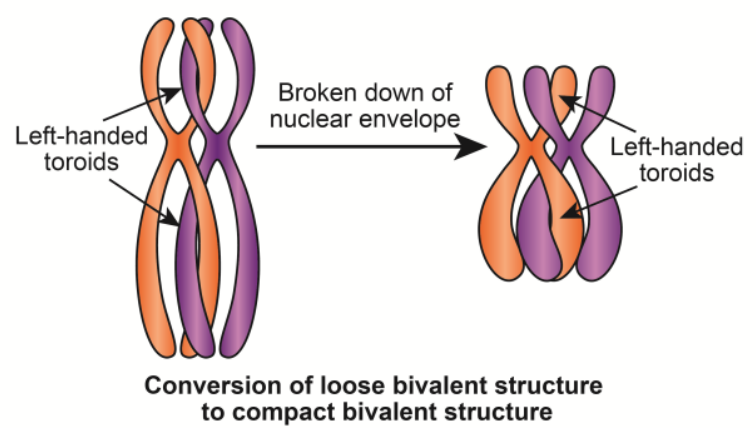

B.

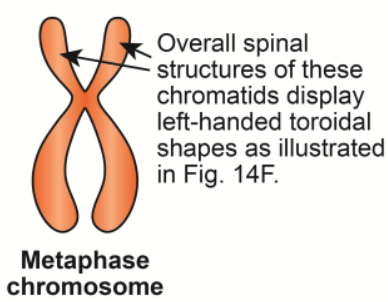

C.

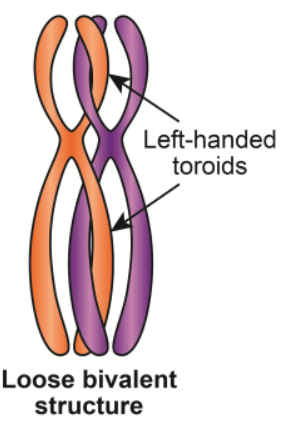

F.

Left-handed toroidal shapes in their overall spinal structures

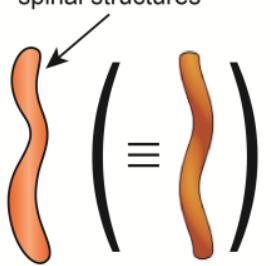

Anaphase chromosome

G.
D.

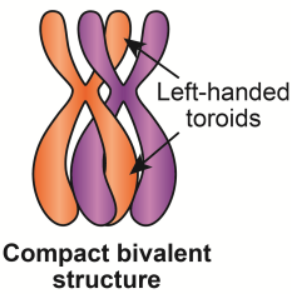
Left-handed toroidal shapes in their overall spinal structures

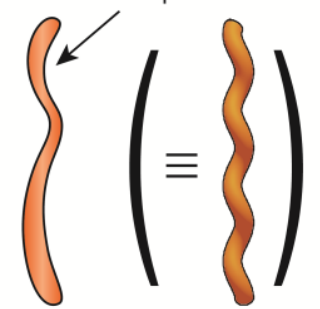

Telophase chromosome

Fig. 14. Illustration of structures of handedness of prophase chromosomes (A), metaphase chromosomes (B), loose bivalent structure (C), compact bivalent structure (D), conversion of 
loose bivalent structure to compact bivalent structure (E), anaphase chromosome and its toroidal spine (F), and telophase chromosome and its toroidal spine $(\mathrm{G})$.

(c) Homologous chromosome-matching zones. It has been known that most of plant and animal cells possess two or more pairs of chromosomes ${ }^{104}$, such as 23 pairs of chromosomes in human cells ${ }^{105}$ and 17 pairs of chromosomes in the cells of sunflowers ${ }^{106}$. Accurate recognition between pairs of homologous chromosomes to form correct bivalent structures is therefore imperative for the subsequent events of chromosomal crossover. ${ }^{71}$ In the current report, existence of "homologous chromosome-matching zones" (or "matching zones") on the surfaces of interconnected loose left-handed helical polyplectoroids (prophase I chromosomes) is suggested, which are responsible (1) for correct recognition between homologous chromosomes and (2) for reducing chances of association between two nonhomologous chromosomes in prophase I of meiosis. These matching zones are composed of different-dimensioned (1) interacting zones and (2) spacer zones that align along columnar structures of prophase chromosomes in alternating manners (Fig. 15A). Interacting zones are the sectors in columnar structures of chromatids that consist predominantly of active insulated neighborhoods while spacer zones are mainly composed of salient and inactive insulated neighborhoods (Fig. 15A). The physical interactions between spacer zones from homologous chromosomes in loose bivalent structures are insignificant owing to their possessions of salient and inactive insulated neighborhoods. Instead, it is the physical interactions of interacting zones between two chromatids from separate pairs of homologous chromosomes that are mainly responsible for holding loose bivalent structures together. Because homologous chromosomes share the same patterns of alternating interacting zones and spacer zones, they are pairable to form bivalent structures (Fig. 15B). As opposed to homologous chromosomes, non-homologous chromosomes, however, possess (1) different alternating patterns of interacting zones and spacer zones and (2) different DNA sequences in interacting zones in their columnar structures. These differences reduce likelihoods of formation of bivalents between non-homologous chromosomes (Fig. 15C).

Even though homologous chromosome-matching zones exist, repulsion effects of enormous amount of negative charges in genomic DNA prevent pairs of homologous chromosomes from spontaneously approaching each other to form bivalent structures. To overcome these electric repulsions, particular membrane proteins emerge concurrently that will bind to sister chromatids and bring them in a close proximity. ${ }^{107-110}$ Once pairs of homologous chromosomes are brought together by these membrane proteins ${ }^{111-112}$, they will be able to form bivalents because they possess identical homologous chromosome-matching zones between them. In contrast to homologous chromosomes, pairs of non-homologous chromosomes have diminishing chances to form bivalent structures because they possess non-identical homologous chromosome-matching zones in their structures.

On the molecular scales, on the other hand, interacting zones at the same loci of two chromatids from separate pairs of sister chromatids recognize and interact with each other by following two sequential steps of events: (1) generation of single stranded DNA from duplex DNA, a process that is driven by pre-existing negative supercoils in their naked linker DNA 
regions; and (2) formation of duplex DNA by two single stranded DNA from two separate sister chromatids, which is assisted by condensin I as this protein complex is known to be able facilitate the generation of duplex DNA structures from their single stranded precursors 113. Because the same loci of homologous chromosomes are known to possess identical DNA sequences in general ${ }^{114}$, this identicalness in sequence makes it possible to form duplex DNA structures by separate pairs of sister chromatids. Deduction 14 is accordingly presented in the current report for describing roles of homologous chromosome-matching zones in formation of bivalent structures:

Deduction 14. Homologous chromosome-matching zones are present in interconnected left-handed loose helical polyplectoroids, which are accountable for (1) correct formation of loose bivalent structures by two pairs of homologous chromosomes (Fig. 15B). Electric repulsions between pairs of homologous chromosomes during formation of loose bivalents are overcome by actions of membrane-binding proteins and other molecules that characteristically emerge during meiosis.

A.

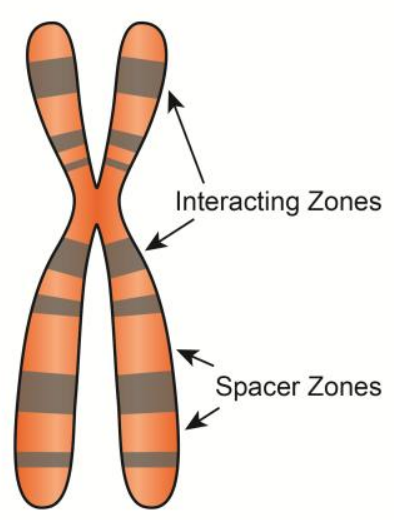

B.

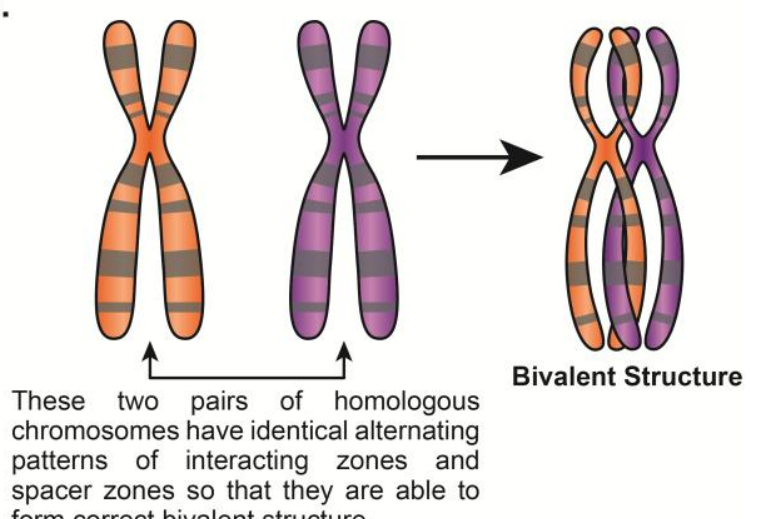

C.
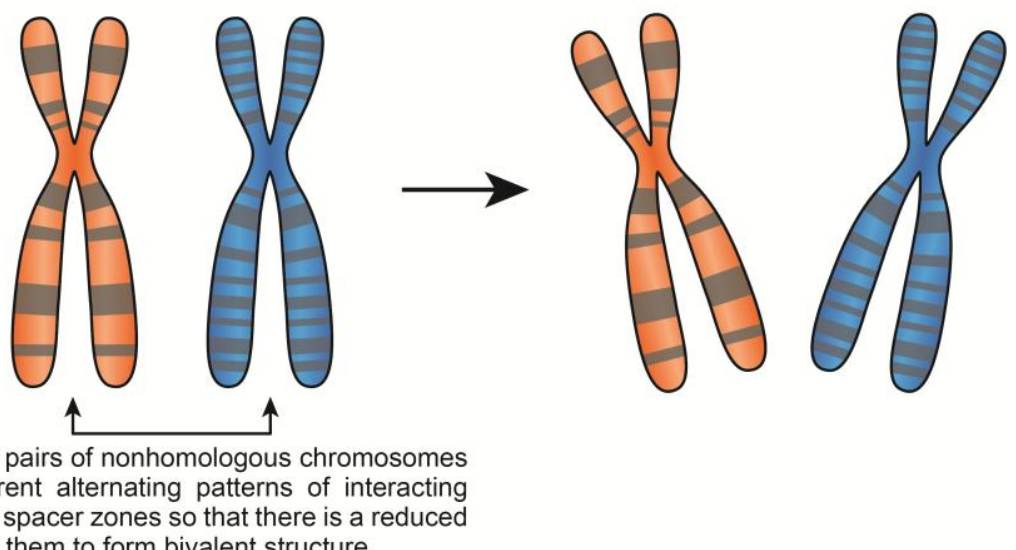

These two pairs of nonhomologous chromosomes have different alternating patterns of interacting zones and spacer zones so that there is a reduced chance for them to form bivalent structure.

Fig. 15. Illustration of presence of homologous chromosome-matching zones on prophase I chromosomes (interconnected loose left-handed helical polyplectoroids) (A), formation of a correct bivalent structure between two pairs of homologous chromosomes through recognition of identical patterns of matching zones (B), and reduced chances for pair of nonhomologous chromosomes to form bivalent structures because they do not possess identical matching zones $(\mathrm{C})$. 


\subsection{Left-handed toroidal structures of protamine-bound DNA and their higher hierarchical architectures as physical forms of post-metaphase chromosomes in sperm cells}

In conjunction with transformation of secondary spermatocytes to haploid spermatids during meiosis II in spermiogenesis, sister chromatids turned into separated chromatids. ${ }^{114}$ In the subsequent Golgi phase of spermiogenesis, DNA in these separated chromatids dissociate from histone proteins to form complexes with transition proteins. ${ }^{115-116}$ Protamines will emerge then to replace transition proteins to generate DNA-protamine toroids. ${ }^{115-118}$ From the supercoiling standard point, protein-unbound DNA regions in protamine toroids of sperm cells should be negatively supercoiled as well. According to Axiom 1, DNA-protamine toroids in sperm cells should display left-handedness because of presence of negative supercoils in their protein-free DNA regions. Deduction 15 is accordingly presented in the current report for describing correlation between shapes, handedness and supercoils in DNAprotamine toroids in sperm cells:

Deduction 15: DNA-protamine toroids in sperm cells (1) are left handed and (2) possess negative supercoils in their protein-unbound DNA regions whereas DNA supercoils in the toroidal structures cannot be resolved by topoisomerase mainly because they possess comparably low superhelical densities. Besides DNA-protamine toroids ${ }^{115-118}$, overall spatial organizations of (a) side-by-side stacked protamine toroids ${ }^{119}$ and (b) bulky assemblies of side-by-side stacked protamine toroids ${ }^{119}$ are determined by negative DNA supercoils that are present in their protein-free DNA regions.

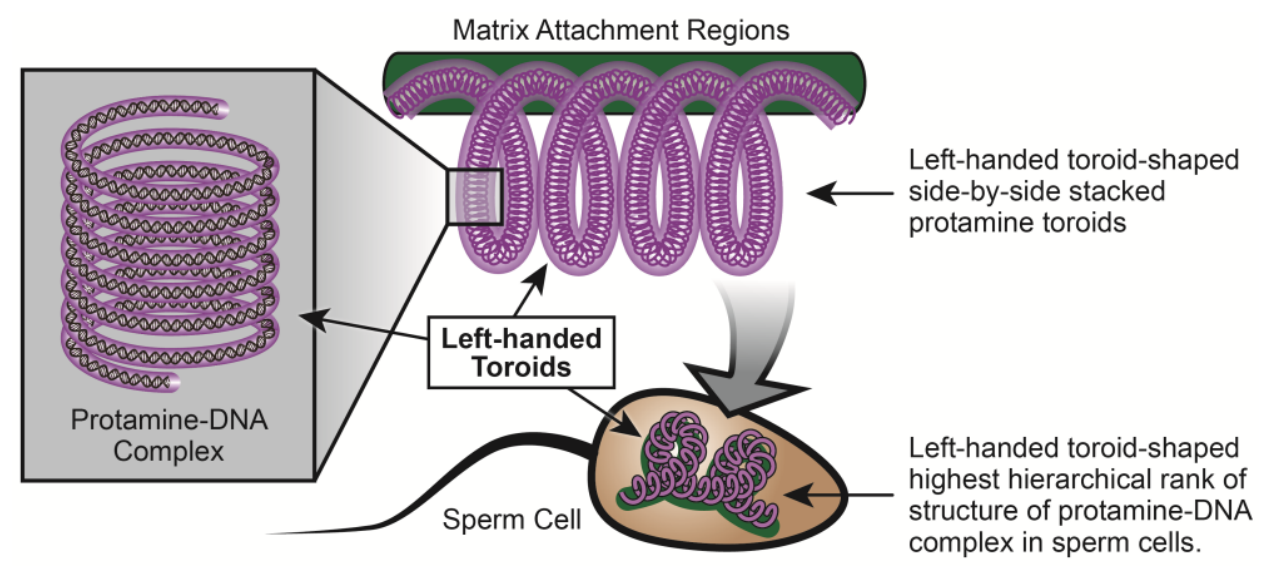

Fig. 16. Supercoiling views of shapes, sign and handedness of protamine-DNA toroids and their higher hierarchical architectures in the sperm cells.

\section{Supercoiling View of Roles of Noncoding DNA in Maintaining Structures and Functions of Eukaryotic Chromosomes}

Noncoding DNA refers commonly to DNA sequences in an organism that do not encode information of proteins ${ }^{120-121}$. Even though protein translation is not advanced on these nucleic acids, various cellular roles of noncoding DNA have been recognized in the past ${ }^{122-}$ 125, which include (1) their transcriptions into functional noncoding RNA such as ribosomal 
RNA, transfer RNA and microRNA ${ }^{122,126-127}$, and (2) their functions as telomeres ${ }^{128-129}$, centromeres and origins of DNA replication ${ }^{128,130}$. From the DNA supercoiling standpoint, noncoding DNA sequences are essential for maintaining supercoil-driven plectonemic and toroidal structures of polynucleosomes in chromosomes of eukaryotic cells as discussed in the five sections below.

\subsection{Noncoding DNA as components of plectonemic and toroidal structures of polynucleosomes for maintaining proper positions of crossover points in insulated neighborhoods.}

Crossover points of polynucleosomal backbones occur in insulated neighborhoods, which are the manifestation of non-zero writhe number of supercoiling-affiliated structures (Deduction 3). Once pairable DNA elements (e.g. enhancers, silencers, promoters, insulators as well as pairs of CTCF) emerge and clasped at these crossover points, they contribute to regulation of gene expressions in their host insulated neighborhoods (Deduction 4). Deduction 16 is accordingly presented below for describing essentialness of noncoding DNA in maintaining spatial organizations of plectonemic and toroidal structures:

Deduction 16. Presence of noncoding DNA sequences is essential for sustaining the rise of pairable elements (e.g. enhancers, silencers, promoters, insulators as well as pairs of CTCF) at crossover points of plectonemic and toroidal structures of polynucleosomes, which are accountable for regulation of gene expressions in their host insulated neighborhoods.

5.2 Vital correlation of transposons with (i) cell types, (ii) genetic diversity, (iii) diverse structural variants in brain cells and (iv) adaptive roles of transposable elements.

It has been known that both inactive transposons and active transposons belong to the category of noncoding DNA sequences. ${ }^{131-132}$ Inactive transposons are incapable of jumping from one place to another in genomic DNA in our time due to the loss of their corresponding transposase gene ${ }^{132}$, and has been considered to be genetic fossils ${ }^{133-134}$. Unlike inactive transposons, on the other hand, active transposons are capable of rearranging themselves alongside genomic DNA nowadays. ${ }^{135-136}$ As discussed in Section of 3.3(d) in the current report, transpositions of these transposons are critically important to eukaryotic cells for their innate functions. Therefore, essentialness of active transposons as noncoding DNA in chromosomes in eukaryotic cells is accordingly presented as follows:

Deduction 17: Because their actions are able to alter three-dimensional structures of insulated neighborhoods and crossover points of polynucleosome backbones, transposons as noncoding DNA are essential (1) for sustaining distinct cell types, (2) for making up genetic diversity in a species' population, (3) for producing diverse structural variants in brain cells, and (4) for enabling organism to adapt gene expressions to environment changes through mechanisms of transposon-induced adaptation.

5.3 Centromeres as noncoding DNA sequences for preventing structural distortion of centromeric regions in sister chromatid pairs. 
When a cell divides, each of its two daughter cells must receive a full and intact copy of genetic material. If any unequal division of genetic material between two daughter cells occurs, defective cells will be resulted. ${ }^{137-138}$ Centromere, on the other hand, is a type of noncoding DNA that makes up of up to $5 \%$ of entire eukaryotic genomic DNA sequences ${ }^{139-}$ ${ }^{141}$, and is believed to play vital roles in cell division cycles ${ }^{141-143}$. From the DNA supercoiling and structural standpoints, there are three characteristics in the spatial organizations of centromere regions:

(1) High stability of centromeric nucleosomal structures. DNA sequences in the portions of regional centromeres are made of repetitive alpha satellite DNA, which is composed of 171base paired particular DNA segments. ${ }^{130,144-145}$ It has been known that nucleosome structures formed by these alpha satellite DNA repeats resemble those generated between 601 elements and histone octamers ${ }^{146}$, which signifies that the nucleosomal structures in the eukaryotic centromeric regions are enormously stable.

(2) High compactness of centromeric $30 \mathrm{~nm}$ fibers. Length of a linker DNA is often defined as the number of base pairs of a DNA segment that resides between two adjacent nucleosome core particles ${ }^{147}$, whose average length in eukaryotic cells is $\sim 55$ base pairs ${ }^{148-149}$. Centromeric polynucleosomes, on the other hand, possess $\sim 25$ base pairs (171 base pairs 146 base pairs = 25 base pairs) in their linker DNA, which is much shorter than overall average length of linker DNA in eukaryotic chromosomes. In other words, the $30 \mathrm{~nm}$ fibers in centromeric regions belong to the category of extraordinarily compact $30 \mathrm{~nm}$ fibers, whose compactness is much higher than those in non-centromeric regions in eukaryotic chromosomes.

\section{(3) High negative superhelical density in naked linker DNA regions in centromeric $30 \mathrm{~nm}$}

fibers. It is known that eukaryotic centromeres can be classified into (1) point centromeres and (2) regional centromeres respectively. ${ }^{150}$ Certain previous studies unveiled that DNA segments within nucleosomes formed by point centromeres were positively supercoiled, which was affiliated with the presence of centromeric histone $\mathrm{H} 3$ in their constituent histone octamers. ${ }^{151-153}$ From the DNA supercoiling viewpoint, in affiliation with these positive supercoils of DNA in point centromere nucleosomes, extra negative supercoils must be generated simultaneously in naked DNA linker segments in centromere regions. Besides point centromeres, if regional centromeres held positive supercoils in their centromeric nucleosomes as well as point centromeres do ${ }^{151-153}$, higher negative superhelical densities would in theory be accumulated in naked linker DNA regions across the entire centromere regions in regional centromere-holding cells. These higher negative superhelical densities will in principle greatly enhance structural firmness of left-handed helical polyplectoroids in centromeric regions in sister chromatid pairs.

In view of the aforementioned structural characteristics of regional centromeres, Deduction 18 is presented in the current report for describing the essentialness of noncoding DNA as components of centromeres during cell division cycles:

Deduction 18. The major roles of noncoding DNA in centromeric regions of sister 
chromatid pairs are (1) to form highly stable structures of centromeric nucleosomes, (2) to generate high structural compactness of centromeric $30 \mathrm{~nm}$ fibers, and (3) to produce high negative superhelical density in naked linker DNA regions of centromeric polynucleosomes, which prevent sister chromatid pairs from structural distortions caused by pulling force-affiliated physical tensions at kinetochore-microtubule interface during separations of the pairs in early anaphase of cell division cycles.

\subsection{Noncoding DNA sequences as components of spacer zones in prophase I chromosomes for correct formation of bivalent structures between homologous chromosomes.}

As discussed in Section 4.3(C) in the current report, homologous chromosome matching zones are associated with columnar structures of prophase and metaphase chromosomes. Within the homologous chromosome matching zones, spacer zones are composed of noncoding DNA whose quantities and dimensions are critically important for achieving correct recognition between two pairs of homologous chromosomes (Deduction 14). Deduction 19 are therefore presented below for describing essentialness of noncoding DNA as parts of homologous chromosome matching zones:

Deduction 19. Presence of noncoding DNA sequences as components of spacer zones in chromosomes in prophase I are imperative for specific recognitions between two pairs of homologous chromosomes to form correct bivalent structures in the pachynema stage of meiosis during cell division cycles.

\subsection{Noncoding DNA sequences as constituents of lamina-associated domains and nucleolus-associated domains for maintaining cellular functions of interphase chromosomes}

The nucleic acid components in both (1) lamina-associated domains ${ }^{84}$ and (2) nucleolusassociated domains ${ }^{85-86}$ consist of inactive and silent topologically associating domains, which are in the category of noncoding DNA. Lamina-associated domains are particular genomic regions that physically interact with nuclear lamina and constitute $\sim 40 \%$ of the human genome. ${ }^{154-155}$ These domains are known to be vital for directing spatial folding of chromosomes in the interphase nucleuses and for regulating DNA replication and gene expressions. $^{84}$ Different from lamina-associated domains, on the other hand, nucleolusassociated domains bind to nucleolus instead. ${ }^{85}$ These domains make up $\sim 4 \%$ of the genome $^{156}$, and are known to be affiliated with nucleolus functions. ${ }^{86}$ Necessity of noncoding DNA as components of lamina-associated domains and nucleolus-associated domains is therefore summarized as follows:

Deduction 20. Noncoding DNA sequences are constituents of lamina-associated domains and nucleolus-associated domains, which are essential for sustaining structures and cellular functions of interphase chromosomes on the whole in eukaryotic cells. 


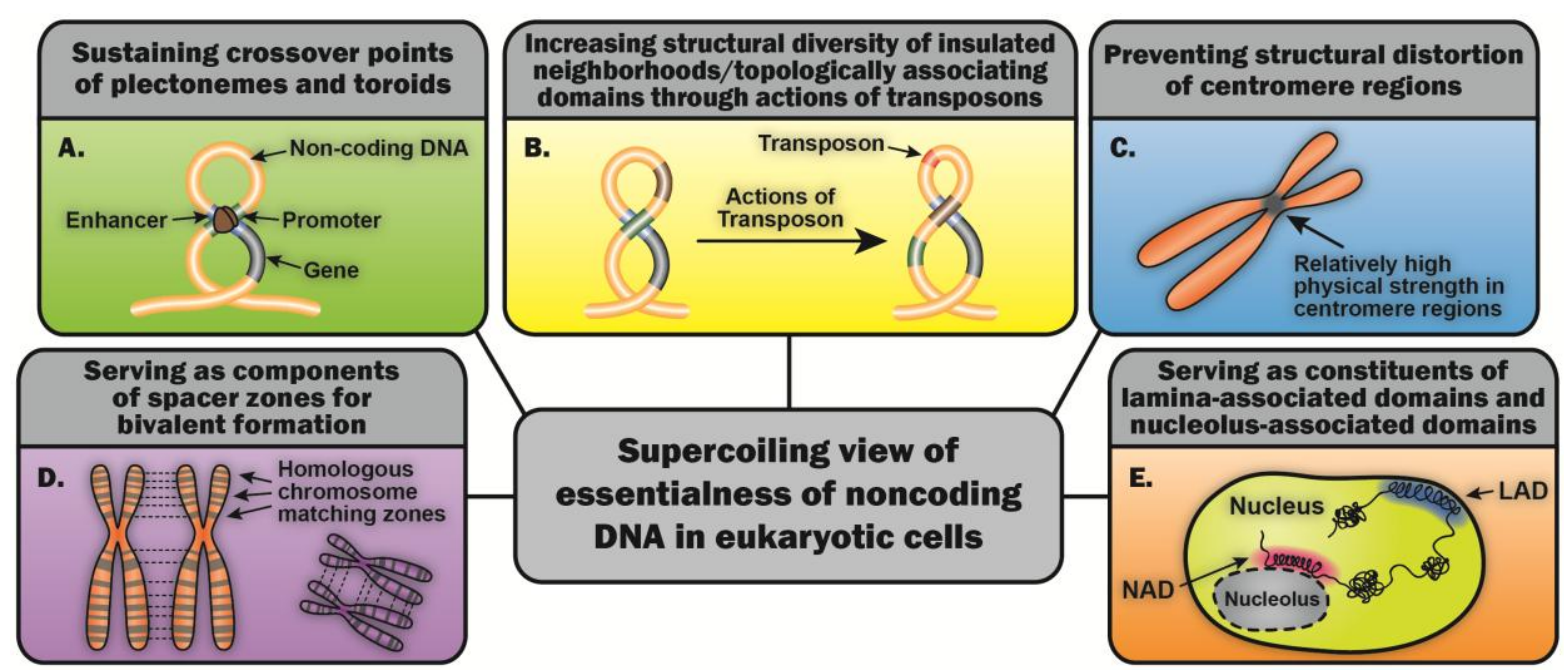

Fig. 17. Illustration of essentialness of noncoding DNA sequences (A) as structural components of plectonemes/toroids of polynucleosomes, (B) in the forms of transposons to alternate shapes, sizes and crossover points of insulated neighborhoods, (C) as structural components to prevent distortion of centromeric regions, (D) as constituents of spacer zones for specific recognition between pairs of homogenous chromosomes, and (E) as constituents of LADs and NADs for maintaining cellular functions of interphase chromosomes.

\section{Conclusion}

With the aim of acquiring new knowledge of mystifying spatial features of eukaryotic chromosomes, a series of experimental examinations on sublevel architectures of chromosomes have been carried out by our group in the past two years. ${ }^{29-32}$ From these studies, four types of previously unknown supercoiling properties of linker DNA, histone H1, nucleosomal structures and polynucleosomes were discovered. ${ }^{29-32}$ Because the only conformation-alterable elements in structures of eukaryotic chromosomes are their naked linker DNA, it is our conviction that these protein-free DNA segments play decisive roles in determining spatial organizations of chromosomes. Consequently, on the foundation of our previous four discoveries ${ }^{29-32}$ and commonly accepted axioms ${ }^{1-2,33-34}$, eukaryotic chromosomal architectures are analyzed from the viewpoints of shapes, signs and handedness of DNA supercoils in the current report. Our intention in presenting the analyses and deductions is to inspire future in-depth endeavors to systematically elucidate sophisticated and subtle molecular architectures of eukaryotic chromosomes from both theoretical and experimental perspectives.

\section{Acknowledgments}

This work was supported by Ministry of Education in Singapore, Nanyang Technological University and Agency for Science, Technology and Research in Singapore through research Grants to Tianhu Li (MOE2014-T2-2-042, MOE RG14/15, MOE RG13/16, MOE RG117/17 and SERC A1883c0007). 


\section{References:}

1. Bates, A. D.; Bates, S. B. S. A. D.; Maxwell, A.; Maxwell, H. D. B. C. A., DNA Topology. Oxford University Press: 2005.

2. $\quad$ Sinden, R. R., DNA Structure and Function. Elsevier Science: 2012.

3. Postow, L.; Hardy, C. D.; Arsuaga, J.; Cozzarelli, N. R., Topological domain structure of the Escherichia coli chromosome. Genes Dev 2004, 18 (14), 1766-79.

4. Musgrave, D.; Forterre, P.; Slesarev, A., Negative constrained DNA supercoiling in archaeal nucleosomes. Mol Microbiol 2000, 35 (2), 341-9.

5. Freeman, L. A.; Garrard, W. T., DNA supercoiling in chromatin structure and gene expression. Critical reviews in eukaryotic gene expression 1992, 2 (2), 165-209.

6. Gilbert, N.; Allan, J., Supercoiling in DNA and chromatin. Current opinion in genetics \& development 2014, 25, 15-21.

7. Champoux, J. J., DNA topoisomerases: Structure, function, and mechanism. Annu Rev Biochem 2001, 70, 369-413.

8. Cozzarelli, N. R., DNA Gyrase and the Supercoiling of DNA. Science 1980, 207 (4434), 953-960.

9. Wu, H. Y.; Shyy, S.; Wang, J. C.; Liu, L. F., Transcription Generates Positively and Negatively Supercoiled Domains in the Template. Cell 1988, 53 (3), 433-440.

10. Forterre, P.; Bergerat, A.; LopezGarcia, P., The unique DNA topology and DNA topoisomerases of hyperthermophilic archaea. Fems Microbiol Rev 1996, 18 (2-3), 237248.

11. Delatour, C. B.; Portemer, C.; Nadal, M.; Stetter, K. O.; Forterre, P.; Duguet, M., Reverse Gyrase, a Hallmark of the Hyperthermophilic Archaebacteria. J Bacteriol 1990, 172 (12), 6803-6808.

12. Marko, J. F.; Siggia, E. D., Fluctuations and Supercoiling of DNA. Science 1994, 265 (5171), 506-508.

13. Esposito, F.; Sinden, R. R., Supercoiling in Prokaryotic and Eukaryotic DNA - Changes in Response to Topological Perturbation of Plasmids in Escherichia-Coli and Sv40 Invitro, in Nuclei and in Cv-1 Cells. Nucleic Acids Res 1987, 15 (13), 5105-5124.

14. Kouzine, F.; Gupta, A.; Baranello, L.; Wojtowicz, D.; Ben-Aissa, K.; Liu, J. H.; Przytycka, T. M.; Levens, D., Transcription-dependent dynamic supercoiling is a shortrange genomic force. Nature structural \& molecular biology 2013, 20 (3), 396-403.

15. Drlica, K., Control of Bacterial-DNA Supercoiling. Mol Microbiol 1992, 6 (4), 425-433.

16. Witz, G.; Stasiak, A., DNA supercoiling and its role in DNA decatenation and unknotting. Nucleic Acids Res 2010, 38 (7), 2119-2133.

17. Schvartzman, J. B.; Martinez-Robles, M. L.; Hernandez, P.; Krimer, D. B., The benefit of DNA supercoiling during replication. Biochemical Society transactions 2013, 41, 646-651.

18. Baranello, L.; Levens, D.; Gupta, A.; Kouzine, F., The importance of being supercoiled: How DNA mechanics regulate dynamic processes. Bba-Gene Regul Mech 2012, 1819 (7), 632-638.

19. Marko, J. F.; Siggia, E. D., Statistical-Mechanics of Supercoiled DNA. Phys Rev E 1995, 52 (3), 2912-2938.

20. van Loenhout, M. T. J.; de Grunt, M. V.; Dekker, C., Dynamics of DNA Supercoils. Science 2012, 338 (6103), 94-97.

21. Gilbert, N.; Allan, J., Supercoiling in DNA and chromatin. Current opinion in genetics \& development 2014, 25, 15-21.

22. Fuller, F. B., Decomposition of the linking number of a closed ribbon: A problem from molecular biology. P Natl Acad Sci USA 1978, 75 (8), 3557-3561. 
23. Călugăreanu, G., Sur les classes d'isotopie des noeuds tridimensionnels et leurs invariants. Czechoslovak Mathematical Journal 1961, 11 (4), 588-625.

24. White, J. H., Self-Linking and the Gauss Integral in Higher Dimensions. American Journal of Mathematics 1969, 91 (3), 693-728.

25. Fuller, F. B., The Writhing Number of a Space Curve. P Natl Acad Sci USA 1971, 68 (4), 815-819.

26. BENHAM, C.; MILLER, D., WRITHING AND LINKING DENSITIES FOR CLOSED, CIRCULAR DNA. J Knot Theor Ramif 2000, 09 (05), 577-585.

27. MILLER, D.; BENHAM, C., FIXED-WRITHE ISOTOPIES AND THE TOPOLOGICAL CONSERVATION LAW FOR CLOSED, CIRCULAR DNA. $J$ Knot Theor Ramif 1996, 05 (06), 859-866.

28. Li, D. W.; Yang, Z. Q.; Zhao, G. J.; Long, Y.; Lv, B.; Li, C.; Hiew, S.; Ng, M. T. T.; Guo, J. J.; Tan, H.; Zhang, H.; Li, T. H., Manipulating DNA writhe through varying DNA sequences. Chemical communications 2011, 47 (26), 7479-7481.

29. Zhang, H.; Li, T. H., Presence of negative supercoiling in aggregates of histone H1plasmidic polynucleosome complexes. Bioorg Med Chem Lett 2017, 27 (2), 168-170.

30. Zhang, H.; Li, T. H., Effects of spermidine and ATP on stabilities of chromatosomes and histone H1-depleted chromatosomes. Bioorg Med Chem Lett 2017, 27 (5), 11491153.

31. Zhang, H.; Li, T. H., Quantitative determination of linking number differences between circular polynucleosomes and histone H1-bound circular polynucleosomes. Bioorg Med Chem Lett 2018, 28 (3), 537-540.

32. Zhang, H.; Li, T., Dataset on the effects of spermidine on linking number differences between histone H1-free and histone H1-bound circular polynucleosomes. Data in Brief 2018, 17, 709-715.

33. Travers, A.; Muskhelishvili, G., A common topology for bacterial and eukaryotic transcription initiation? Embo Rep 2007, 8 (2), 147-151.

34. Argudo, D.; Purohit, P. K., Competition between Supercoils and Toroids in Single Molecule DNA Condensation. Biophys J 2012, 103 (1), 118-128.

35. Crick, F. H. C., Linking Numbers and Nucleosomes. P Natl Acad Sci USA 1976, 73 (8), 2639-2643.

36. Hizume, K.; Araki, S.; Yoshikawa, K.; Takeyasu, K., Topoisomerase II, scaffold component, promotes chromatin compaction in vitro in a linker-histone H1-dependent manner. Nucleic Acids Res 2007, 35 (8), 2787-2799.

37. Wacker, D. A.; Ruhl, D. D.; Balagamwala, E. H.; Hope, K. M.; Zhang, T.; Kraus, W. L., The DNA Binding and Catalytic Domains of Poly(ADP-Ribose) Polymerase 1 Cooperate in the Regulation of Chromatin Structure and Transcription. Molecular and cellular biology 2007, 27 (21), 7475-7485.

38. Irobalieva, R. N.; Fogg, J. M.; Catanese, D. J.; Sutthibutpong, T.; Chen, M. Y.; Barker, A. K.; Ludtke, S. J.; Harris, S. A.; Schmid, M. F.; Chiu, W.; Zechiedrich, L., Structural diversity of supercoiled DNA. Nat Commun 2015, 6.

39. Pavlicek, J. W.; Oussatcheva, E. A.; Sinden, R. R.; Potaman, V. N.; Sankey, O. F.; Lyubchenko, Y. L., Supercoiling-induced DNA bending. Biochemistry 2004, 43 (33), 10664-10668.

40. Deng, H.; Bloomfield, V. A.; Benevides, J. M.; Thomas, G. J., Structural basis of polyamine-DNA recognition: spermidine and spermine interactions with genomic BDNAs of different GC content probed by Raman spectroscopy. Nucleic Acids Res 2000, 28 (17), 3379-3385.

41. Watson, J. D.; Crick, F. H. C., Molecular Structure of Nucleic Acids - a Structure for Deoxyribose Nucleic Acid. Nature 1953, 171 (4356), 737-738. 
42. Kornberg, R. D., Chromatin Structure: A Repeating Unit of Histones and DNA. Science 1974, 184 (4139), 868-871.

43. Cutter, A. R.; Hayes, J. J., A brief review of nucleosome structure. Febs Lett 2015, 589 (20), 2914-2922.

44. Luger, K.; Mader, A. W.; Richmond, R. K.; Sargent, D. F.; Richmond, T. J., Crystal structure of the nucleosome core particle at 2.8 angstrom resolution. Nature 1997, 389 (6648), 251-260.

45. Bednar, J.; Horowitz, R. A.; Grigoryev, S. A.; Carruthers, L. M.; Hansen, J. C.; Koster, A. J.; Woodcock, C. L., Nucleosomes, linker DNA, and linker histone form a unique structural motif that directs the higher-order folding and compaction of chromatin. Proceedings of the National Academy of Sciences 1998, 95 (24), 14173-14178.

46. van Holde, K. E., Chromatin. Springer New York: 2012.

47. Szerlong, H. J.; Hansen, J. C., Nucleosome distribution and linker DNA: connecting nuclear function to dynamic chromatin structure. Biochemistry and cell biology = Biochimie et biologie cellulaire 2011, 89 (1), 24-34.

48. Robinson, P. J. J.; Fairall, L.; Huynh, V. A. T.; Rhodes, D., EM measurements define the dimensions of the "30-nm" chromatin fiber: Evidence for a compact, interdigitated structure. P Natl Acad Sci USA 2006, 103 (17), 6506-6511.

49. Schalch, T.; Duda, S.; Sargent, D. F.; Richmond, T. J., X-ray structure of a tetranucleosome and its implications for the chromatin fibre. Nature 2005, 436 (7047), 138-141.

50. Song, F.; Chen, P.; Sun, D. P.; Wang, M. Z.; Dong, L. P.; Liang, D.; Xu, R. M.; Zhu, P.; Li, G. H., Cryo-EM Study of the Chromatin Fiber Reveals a Double Helix Twisted by Tetranucleosomal Units. Science 2014, 344 (6182), 376-380.

51. Luijsterburg, M. S.; White, M. F.; van Driel, R.; Dame, R. T., The Major Architects of Chromatin: Architectural Proteins in Bacteria, Archaea and Eukaryotes. Critical reviews in biochemistry and molecular biology 2008, 43 (6), 393-418.

52. Dowen, J. M.; Fan, Z. P.; Hnisz, D.; Ren, G.; Abraham, B. J.; Zhang, L. N.; Weintraub, A. S.; Schuijers, J.; Lee, T. I.; Zhao, K. J.; Young, R. A., Control of Cell Identity Genes Occurs in Insulated Neighborhoods in Mammalian Chromosomes. Cell 2014, 159 (2), 374-387.

53. Hnisz, D.; Day, D. S.; Young, R. A., Insulated Neighborhoods: Structural and Functional Units of Mammalian Gene Control. Cell 2016, 167 (5), 1188-1200.

54. Ji, X.; Dadon, D. B.; Powell, B. E.; Fan, Z. P.; Borges-Rivera, D.; Shachar, S.; Weintraub, A. S.; Hnisz, D.; Pegoraro, G.; Lee, T. I.; Misteli, T.; Jaenisch, R.; Young, R. A., 3D Chromosome Regulatory Landscape of Human Pluripotent Cells. Cell stem cell 2016, 18 (2), 262-275.

55. Abuelo, J. G.; Moore, D. E., THE HUMAN CHROMOSOME. Electron Microscopic Observations on Chromatin Fiber Organization 1969, 41 (1), 73-90.

56. Reznik, N. A.; Yampol, G. P.; Kiseleva, E. V.; Khristolyubova, N. B.; Gruzdev, A. D., Functional and Structural Units in the Chromomere. Genetica 1991, 83 (3), 293-299.

57. Kulikova, T.; Khodyuchenko, T.; Petrov, Y.; Krasikova, A., Low-voltage scanning electron microscopy study of lampbrush chromosomes and nuclear bodies in avian and amphibian oocytes. Sci Rep-Uk 2016, 6.

58. Fogg, J. M.; Catanese, D. J.; Randall, G. L.; Swick, M. C.; Zechiedrich, L., Differences between Positively and Negatively Supercoiled DNA That Topoisomerases May Distinguish. Ima Vol Math Appl 2009, 150, 73-+.

59. Griffiths, A. J. F.; Depaula, A.; Young, P.; Miller, J. H.; Suzuki, D. T.; Lewontin, R. C.; Gelbart, W. M., An Introduction to Genetic Analysis. Macmillan Higher Education: 2003. 
60. Tjian, R., Molecular Machines That Control Genes. Sci Am 1995, 272 (2), 54-61.

61. Gaszner, M.; Felsenfeld, G., Insulators: exploiting transcriptional and epigenetic mechanisms. Nat Rev Genet 2006, 7 (9), 703-713.

62. Kadauke, S.; Blobel, G. A., Chromatin loops in gene regulation. Bba-Gene Regul Mech 2009, 1789 (1), 17-25.

63. Pope, B. D.; Ryba, T.; Dileep, V.; Yue, F.; Wu, W. S.; Denas, O.; Vera, D. L.; Wang, Y. L.; Hansen, R. S.; Canfield, T. K.; Thurman, R. E.; Cheng, Y.; Gulsoy, G.; Dennis, J. H.; Snyder, M. P.; Stamatoyannopoulos, J. A.; Taylor, J.; Hardison, R. C.; Kahveci, T.; Ren, B.; Gilbert, D. M., Topologically associating domains are stable units of replication-timing regulation. Nature 2014, 515 (7527), 402-+.

64. Dixon, J. R.; Gorkin, D. U.; Ren, B., Chromatin Domains: The Unit of Chromosome Organization. Molecular cell 2016, 62 (5), 668-680.

65. Ulianov, S. V.; Khrameeva, E. E.; Gavrilov, A. A.; Flyamer, I. M.; Kos, P.; Mikhaleva, E. A.; Penin, A. A.; Logacheva, M. D.; Imakaev, M. V.; Chertovich, A.; Gelfand, M. S.; Shevelyov, Y. Y.; Razin, S. V., Active chromatin and transcription play a key role in chromosome partitioning into topologically associating domains. Genome Research 2016, 26 (1), 70-84.

66. Frost, L. S.; Leplae, R.; Summers, A. O.; Toussaint, A., Mobile genetic elements: The agents of open source evolution. Nat Rev Microbiol 2005, 3 (9), 722-732.

67. Feschotte, C.; Pritham, E. J., DNA transposons and the evolution of eukaryotic genomes. Annu Rev Genet 2007, 41, 331-368.

68. Lesbats, P.; Engelman, A. N.; Cherepanov, P., Retroviral DNA Integration. Chemical reviews 2016, 116 (20), 12730-12757.

69. Koonin, E. V.; Dolja, V. V.; Krupovic, M., Origins and evolution of viruses of eukaryotes: The ultimate modularity. Virology 2015, 479, 2-25.

70. Oliver, K. R.; Greene, W. K., Transposable elements and viruses as factors in adaptation and evolution: an expansion and strengthening of the TE-Thrust hypothesis. Ecol Evol 2012, 2 (11), 2912-2933.

71. Alberts, B., Molecular Biology of the Cell. CRC Press: 2017.

72. Latchman, D. S., Gene Regulation: A Eukaryotic Perspective. Nelson Thornes: 2002.

73. Rockman, M. V.; Kruglyak, L., Genetics of global gene expression. Nat Rev Genet 2006, 7 (11), 862-872.

74. Holsinger, K. E.; Weir, B. S., FUNDAMENTAL CONCEPTS IN GENETICS Genetics in geographically structured populations: defining, estimating and interpreting F-ST. Nat Rev Genet 2009, 10 (9), 639-650.

75. Morjan, C. L.; Rieseberg, L. H., How species evolve collectively: implications of gene flow and selection for the spread of advantageous alleles. Mol Ecol 2004, 13 (6), 13411356.

76. Erwin, J. A.; Paquola, A. C. M.; Singer, T.; Gallinal, I.; Novotny, M.; Quayle, C.; Bedrosian, T. A.; Alves, F. I. A.; Butcher, C. R.; Herdy, J. R.; Sarkar, A.; Lasken, R. S.; Muotri, A. R.; Gage, F. H., L1-associated genomic regions are deleted in somatic cells of the healthy human brain. Nat Neurosci 2016, 19 (12), 1583-1591.

77. Jangam, D.; Feschotte, C.; Betran, E., Transposable Element Domestication As an Adaptation to Evolutionary Conflicts. Trends Genet 2017, 33 (11), 817-831.

78. Mcclintock, B., The Origin and Behavior of Mutable Loci in Maize. P Natl Acad Sci USA 1950, 36 (6), 344-355.

79. Gonzalez, J.; Petrov, D. A., The adaptive role of transposable elements in the Drosophila genome. Gene 2009, 448 (2), 124-133.

80. Kreth, G.; Finsterle, J.; von Hase, J.; Cremer, M.; Cremer, C., Radial arrangement of chromosome territories in human cell nuclei: A computer model approach based on 
gene density indicates a probabilistic global positioning code. Biophys $J$ 2004, 86 (5), 2803-2812.

81. Meaburn, K. J.; Misteli, T., Cell biology - Chromosome territories. Nature 2007, 445 (7126), 379-381.

82. Cremer, T.; Cremer, M., Chromosome Territories. Cold Spring Harbor Perspectives in Biology 2010, 2 (3), a003889.

83. Cremer, T.; Cremer, C., Chromosome territories, nuclear architecture and gene regulation in mammalian cells. Nat Rev Genet 2001, 2 (4), 292-301.

84. van Steensel, B.; Belmont, A. S., Lamina-Associated Domains: Links with Chromosome Architecture, Heterochromatin, and Gene Repression. Cell 2017, 169 (5), 780-791.

85. Nemeth, A.; Langst, G., Genome organization in and around the nucleolus. Trends Genet 2011, 27 (4), 149-156.

86. Pontvianne, F.; Carpentier, M. C.; Durut, N.; Pavlistova, V.; Jaske, K.; Schorova, S.; Parrinello, H.; Rohmer, M.; Pikaard, C. S.; Fojtova, M.; Fajkus, J.; Saez-Vasquez, J., Identification of Nucleolus-Associated Chromatin Domains Reveals a Role for the Nucleolus in 3D Organization of the A. thaliana Genome. Cell reports 2016, 16 (6), 1574-1587.

87. Belmont, A. S., Mitotic chromosome scaffold structure: New approaches to an old controversy. Proceedings of the National Academy of Sciences 2002, 99 (25), 15855.

88. Goloborodko, A.; Marko, John F.; Mirny, Leonid A., Chromosome Compaction by Active Loop Extrusion. Biophys J 2016, 110 (10), 2162-2168.

89. Marsden, M. P. F.; Laemmli, U. K., Metaphase Chromosome Structure - Evidence for a Radial Loop Model. Cell 1979, 17 (4), 849-858.

90. Earnshaw, W. C.; Laemmli, U. K., Architecture of Metaphase Chromosomes and Chromosome Scaffolds. J Cell Biol 1983, 96 (1), 84-93.

91. Dounce, A. L.; Chanda, S. K.; Townes, P. L., The structure of higher eukaryotic chromosomes. J Theor Biol 1973, 42 (2), 275-285.

92. Takahashi, M., A fractal model of chromosomes and chromosomal DNA replication. $J$ Theor Biol 1989, 141 (1), 117-136.

93. Cooper, G. M., The Cell: A Molecular Approach. ASM Press: 2000.

94. Kimura, K.; Hirano, T., ATP-dependent positive supercoiling of DNA by $13 \mathrm{~S}$ condensin: A biochemical implication for chromosome condensation. Cell 1997, 90 (4), 625-634.

95. Bazett-Jones, D. P.; Kimura, K.; Hirano, T., Efficient supercoiling of DNA by a single condensin complex as revealed by electron spectroscopic imaging. Molecular cell 2002, 9 (6), 1183-1190.

96. Ono, T.; Losada, A.; Hirano, M.; Myers, M. P.; Neuwald, A. F.; Hirano, T., Differential contributions of condensin I and condensin II to mitotic chromosome architecture in vertebrate cells. Cell 2003, 115 (1), 109-121.

97. Peters, J. M.; Tedeschi, A.; Schmitz, J., The cohesin complex and its roles in chromosome biology. Gene Dev 2008, 22 (22), 3089-3114.

98. Green, L. C.; Kalitsis, P.; Chang, T. M.; Cipetic, M.; Kim, J. H.; Marshall, O.; Turnbull, L.; Whitchurch, C. B.; Vagnarelli, P.; Samejima, K.; Earnshaw, W. C.; Choo, K. H. A.; Hudson, D. F., Contrasting roles of condensin I and condensin II in mitotic chromosome formation. J Cell Sci 2012, 125 (6), 1591-1604.

99. Hirano, T., Condensins: universal organizers of chromosomes with diverse functions. Gene Dev 2012, 26 (15), 1659-1678.

100. Heck, M. M. S., Condensins, cohesins, and chromosome architecture: How to make and break a mitotic chromosome. Cell 1997, 91 (1), 5-8. 
101. Pawlowski, W. P.; Cande, W. Z., Coordinating the events of the meiotic prophase. Trends Cell Biol 2005, 15 (12), 674-681.

102. Schvarzstein, M.; Wignall, S. M.; Villeneuve, A. M., Coordinating cohesion, coorientation, and congression during meiosis: lessons from holocentric chromosomes. Gene Dev 2010, 24 (3), 219-228.

103. Heyting, C., Synaptonemal complexes: Structure and function. Curr Opin Cell Biol 1996, 8 (3), 389-396.

104. Peruzzi, L.; Bedini, G., Online resources for chromosome number databases. Caryologia 2014, 67 (4), 292-295.

105. Ford, C. E.; Hamerton, J. L., The Chromosomes of Man. Nature 1956, 178, 1020.

106. Feng, J. H.; Liu, Z.; Cai, X. W.; Jan, C. C., Toward a Molecular Cytogenetic Map for Cultivated Sunflower (Helianthus annuus L.) by Landed BAC/BIBAC Clones. G3Genes Genom Genet 2013, 3 (1), 31-40.

107. Macqueen, A. J.; Phillips, C. M.; Bhalla, N.; Weiser, P.; Villeneuve, A. M.; Dernburg, A. F., Chromosome sites play dual roles to establish homologous synapsis during meiosis in C-elegans. Cell 2005, 123 (6), 1037-1050.

108. Phillips, C. M.; Wong, C.; Bhalla, N.; Carlton, P. M.; Weiser, P.; Meneely, P. M.; Dernburg, A. F., HIM-8 binds to the $\mathrm{X}$ chromosome pairing center and mediates chromosome-specific meiotic synapsis. Cell 2005, 123 (6), 1051-1063.

109. Phillips, C. M.; Meng, X. D.; Zhang, L.; Chretien, J. H.; Urnov, F. D.; Dernburg, A. F., Identification of chromosome sequence motifs that mediate meiotic pairing and synapsis in C. elegans. Nat Cell Biol 2009, 11 (8), 934-U66.

110. Phillips, C. M.; Dernburg, A. F., A family of zinc-finger proteins is required for chromosome-specific pairing and synapsis during meiosis in C. elegans. Dev Cell 2006, $11(6), 817-829$.

111. Wynne, D. J.; Rog, O.; Carlton, P. M.; Dernburg, A. F., Dynein-dependent processive chromosome motions promote homologous pairing in C. elegans meiosis. J Cell Biol 2012, 196 (1), 47-64.

112. de Massy, B., Meiosis: To pair and recombine, a sophisticated chromosome dance. Semin Cell Dev Biol 2016, 54, 104-105.

113. Barzel, A.; Kupiec, M., Finding a match: how do homologous sequences get together for recombination? Nat Rev Genet 2008, 9 (1), 27-37.

114. Egel, R.; Lankenau, D. H., Recombination and Meiosis: Models, Means, and Evolution. Springer Berlin Heidelberg: 2010.

115. Pradeepa, M. M.; Rao, M. R., Chromatin remodeling during mammalian spermatogenesis: role of testis specific histone variants and transition proteins. Society of Reproduction and Fertility supplement 2007, 63, 1-10.

116. Rathke, C.; Baarends, W. M.; Awe, S.; Renkawitz-Pohl, R., Chromatin dynamics during spermiogenesis. Biochimica et biophysica acta 2014, 1839 (3), 155-68.

117. Balhorn, R., The protamine family of sperm nuclear proteins. Genome Biology 2007, 8 (9).

118. Miller, D.; Brinkworth, M.; Iles, D., Paternal DNA packaging in spermatozoa: more than the sum of its parts? DNA, histones, protamines and epigenetics. Reproduction 2010, 139 (2), 287-301.

119. Ward, W. S., Function of sperm chromatin structural elements in fertilization and development. Molecular Human Reproduction 2010, 16 (1), 30-36.

120. Litwack, G., Human Biochemistry. Elsevier Science: 2017.

121. Flintoft, L., Genome evolution - An adaptive view of non-coding DNA. Nat Rev Genet 2005, 6 (12), 880-880. 
122. Dunham, I.; Kundaje, A.; Aldred, S. F.; Collins, P. J.; Davis, C.; Doyle, F.; Epstein, C. B.; Frietze, S.; Harrow, J.; Kaul, R.; Khatun, J.; Lajoie, B. R.; Landt, S. G.; Lee, B. K.; Pauli, F.; Rosenbloom, K. R.; Sabo, P.; Safi, A.; Sanyal, A.; Shoresh, N.; Simon, J. M.; Song, L.; Trinklein, N. D.; Altshuler, R. C.; Birney, E.; Brown, J. B.; Cheng, C.; Djebali, S.; Dong, X. J.; Dunham, I.; Ernst, J.; Furey, T. S.; Gerstein, M.; Giardine, B.; Greven, M.; Hardison, R. C.; Harris, R. S.; Herrero, J.; Hoffman, M. M.; Iyer, S.; Kellis, M.; Khatun, J.; Kheradpour, P.; Kundaje, A.; Lassmann, T.; Li, Q. H.; Lin, X.; Marinov, G. K.; Merkel, A.; Mortazavi, A.; Parker, S. C. J.; Reddy, T. E.; Rozowsky, J.; Schlesinger, F.; Thurman, R. E.; Wang, J.; Ward, L. D.; Whitfield, T. W.; Wilder, S. P.; Wu, W.; Xi, H. L. S.; Yip, K. Y.; Zhuang, J. L.; Bernstein, B. E.; Birney, E.; Dunham, I.; Green, E. D.; Gunter, C.; Snyder, M.; Pazin, M. J.; Lowdon, R. F.; Dillon, L. A. L.; Adams, L. B.; Kelly, C. J.; Zhang, J.; Wexler, J. R.; Green, E. D.; Good, P. J.; Feingold, E. A.; Bernstein, B. E.; Birney, E.; Crawford, G. E.; Dekker, J.; Elnitski, L.; Farnham, P. J.; Gerstein, M.; Giddings, M. C.; Gingeras, T. R.; Green, E. D.; Guigo, R.; Hardison, R. C.; Hubbard, T. J.; Kellis, M.; Kent, W. J.; Lieb, J. D.; Margulies, E. H.; Myers, R. M.; Snyder, M.; Stamatoyannopoulos, J. A.; Tenenbaum, S. A.; Weng, Z. P.; White, K. P.; Wold, B.; Khatun, J.; Yu, Y.; Wrobel, J.; Risk, B. A.; Gunawardena, H. P.; Kuiper, H. C.; Maier, C. W.; Xie, L.; Chen, X.; Giddings, M. C.; Bernstein, B. E.; Epstein, C. B.; Shoresh, N.; Ernst, J.; Kheradpour, P.; Mikkelsen, T. S.; Gillespie, S.; Goren, A.; Ram, O.; Zhang, X. L.; Wang, L.; Issner, R.; Coyne, M. J.; Durham, T.; Ku, M.; Truong, T.; Ward, L. D.; Altshuler, R. C.; Eaton, M. L.; Kellis, M.; Djebali, S.; Davis, C. A.; Merkel, A.; Dobin, A.; Lassmann, T.; Mortazavi, A.; Tanzer, A.; Lagarde, J.; Lin, W.; Schlesinger, F.; Xue, C. H.; Marinov, G. K.; Khatun, J.; Williams, B. A.; Zaleski, C.; Rozowsky, J.; Roeder, M.; Kokocinski, F.; Abdelhamid, R. F.; Alioto, T.; Antoshechkin, I.; Baer, M. T.; Batut, P.; Bell, I.; Bell, K.; Chakrabortty, S.; Chen, X.; Chrast, J.; Curado, J.; Derrien, T.; Drenkow, J.; Dumais, E.; Dumais, J.; Duttagupta, R.; Fastuca, M.; Fejes-Toth, K.; Ferreira, P.; Foissac, S.; Fullwood, M. J.; Gao, H.; Gonzalez, D.; Gordon, A.; Gunawardena, H. P.; Howald, C.; Jha, S.; Johnson, R.; Kapranov, P.; King, B.; Kingswood, C.; Li, G. L.; Luo, O. J.; Park, E.; Preall, J. B.; Presaud, K.; Ribeca, P.; Risk, B. A.; Robyr, D.; Ruan, X. A.; Sammeth, M.; Sandhu, K. S.; Schaeffer, L.; See, L. H.; Shahab, A.; Skancke, J.; Suzuki, A. M.; Takahashi, H.; Tilgner, H.; Trout, D.; Walters, N.; Wang, H. E.; Wrobel, J.; Yu, Y. B.; Hayashizaki, Y.; Harrow, J.; Gerstein, M.; Hubbard, T. J.; Reymond, A.; Antonarakis, S. E.; Hannon, G. J.; Giddings, M. C.; Ruan, Y. J.; Wold, B.; Carninci, P.; Guigo, R.; Gingeras, T. R.; Rosenbloom, K. R.; Sloan, C. A.; Learned, K.; Malladi, V. S.; Wong, M. C.; Barber, G.; Cline, M. S.; Dreszer, T. R.; Heitner, S. G.; Karolchik, D.; Kent, W. J.; Kirkup, V. M.; Meyer, L. R.; Long, J. C.; Maddren, M.; Raney, B. J.; Furey, T. S.; Song, L. Y.; Grasfeder, L. L.; Giresi, P. G.; Lee, B. K.; Battenhouse, A.; Sheffield, N. C.; Simon, J. M.; Showers, K. A.; Safi, A.; London, D.; Bhinge, A. A.; Shestak, C.; Schaner, M. R.; Kim, S. K.; Zhang, Z. Z. Z.; Mieczkowski, P. A.; Mieczkowska, J. O.; Liu, Z.; McDaniell, R. M.; Ni, Y. Y.; Rashid, N. U.; Kim, M. J.; Adar, S.; Zhang, Z. C.; Wang, T. Y.; Winter, D.; Keefe, D.; Birney, E.; Iyer, V. R.; Lieb, J. D.; Crawford, G. E.; Li, G. L.; Sandhu, K. S.; Zheng, M. Z.; Wang, P.; Luo, O. J.; Shahab, A.; Fullwood, M. J.; Ruan, X. A.; Ruan, Y. J.; Myers, R. M.; Pauli, F.; Williams, B. A.; Gertz, J.; Marinov, G. K.; Reddy, T. E.; Vielmetter, J.; Partridge, E. C.; Trout, D.; Varley, K. E.; Gasper, C.; Bansal, A.; Pepke, S.; Jain, P.; Amrhein, H.; Bowling, K. M.; Anaya, M.; Cross, M. K.; King, B.; Muratet, M. A.; Antoshechkin, I.; Newberry, K. M.; Mccue, K.; Nesmith, A. S.; Fisher-Aylor, K. I.; Pusey, B.; DeSalvo, G.; Parker, S. L.; Balasubramanian, S.; Davis, N. S.; Meadows, S. K.; Eggleston, T.; Gunter, C.; Newberry, J. S.; Levy, S. E.; Absher, D. M.; Mortazavi, A.; Wong, W. H.; Wold, B.; Blow, M. J.; Visel, A.; 
Pennachio, L. A.; Elnitski, L.; Margulies, E. H.; Parker, S. C. J.; Petrykowska, H. M.; Abyzov, A.; Aken, B.; Barrell, D.; Barson, G.; Berry, A.; Bignell, A.; Boychenko, V.; Bussotti, G.; Chrast, J.; Davidson, C.; Derrien, T.; Despacio-Reyes, G.; Diekhans, M.; Ezkurdia, I.; Frankish, A.; Gilbert, J.; Gonzalez, J. M.; Griffiths, E.; Harte, R.; Hendrix, D. A.; Howald, C.; Hunt, T.; Jungreis, I.; Kay, M.; Khurana, E.; Kokocinski, F.; Leng, J.; Lin, M. F.; Loveland, J.; Lu, Z.; Manthravadi, D.; Mariotti, M.; Mudge, J.; Mukherjee, G.; Notredame, C.; Pei, B. K.; Rodriguez, J. M.; Saunders, G.; Sboner, A.; Searle, S.; Sisu, C.; Snow, C.; Steward, C.; Tanzer, A.; Tapanari, E.; Tress, M. L.; van Baren, M. J.; Walters, N.; Washietl, S.; Wilming, L.; Zadissa, A.; Zhang, Z. D.; Brent, M.; Haussler, D.; Kellis, M.; Valencia, A.; Gerstein, M.; Reymond, A.; Guigo, R.; Harrow, J.; Hubbard, T. J.; Landt, S. G.; Frietze, S.; Abyzov, A.; Addleman, N.; Alexander, R. P.; Auerbach, R. K.; Balasubramanian, S.; Bettinger, K.; Bhardwaj, N.; Boyle, A. P.; Cao, A. R.; Cayting, P.; Charos, A.; Cheng, Y.; Cheng, C.; Eastman, C.; Euskirchen, G.; Fleming, J. D.; Grubert, F.; Habegger, L.; Hariharan, M.; Harmanci, A.; Iyengar, S.; Jin, V. X.; Karczewski, K. J.; Kasowski, M.; Lacroute, P.; Lam, H.; Lamarre-Vincent, N.; Leng, J.; Lian, J.; Lindahl-Allen, M.; Min, R. Q.; Miotto, B.; Monahan, H.; Moqtaderi, Z.; Mu, X. M. J.; O'Geen, H.; Ouyang, Z. Q.; Patacsil, D.; Pei, B. K.; Raha, D.; Ramirez, L.; Reed, B.; Rozowsky, J.; Sboner, A.; Shi, M. Y.; Sisu, C.; Slifer, T.; Witt, H.; Wu, L. F.; Xu, X. Q.; Yan, K. K.; Yang, X. Q.; Yip, K. Y.; Zhang, Z. D.; Struhl, K.; Weissman, S. M.; Gerstein, M.; Farnham, P. J.; Snyder, M.; Tenenbaum, S. A.; Penalva, L. O.; Doyle, F.; Karmakar, S.; Landt, S. G.; Bhanvadia, R. R.; Choudhury, A.; Domanus, M.; Ma, L. J.; Moran, J.; Patacsil, D.; Slifer, T.; Victorsen, A.; Yang, X. Q.; Snyder, M.; White, K. P.; Auer, T.; Centanin, L.; Eichenlaub, M.; Gruhl, F.; Heermann, S.; Hoeckendorf, B.; Inoue, D.; Kellner, T.; Kirchmaier, S.; Mueller, C.; Reinhardt, R.; Schertel, L.; Schneider, S.; Sinn, R.; Wittbrodt, B.; Wittbrodt, J.; Weng, Z. P.; Whitfield, T. W.; Wang, J.; Collins, P. J.; Aldred, S. F.; Trinklein, N. D.; Partridge, E. C.; Myers, R. M.; Dekker, J.; Jain, G.; Lajoie, B. R.; Sanyal, A.; Balasundaram, G.; Bates, D. L.; Byron, R.; Canfield, T. K.; Diegel, M. J.; Dunn, D.; Ebersol, A. K.; Frum, T.; Garg, K.; Gist, E.; Hansen, R. S.; Boatman, L.; Haugen, E.; Humbert, R.; Jain, G.; Johnson, A. K.; Johnson, E. M.; Kutyavin, T. V.; Lajoie, B. R.; Lee, K.; Lotakis, D.; Maurano, M. T.; Neph, S. J.; Neri, F. V.; Nguyen, E. D.; Qu, H. Z.; Reynolds, A. P.; Roach, V.; Rynes, E.; Sabo, P.; Sanchez, M. E.; Sandstrom, R. S.; Sanyal, A.; Shafer, A. O.; Stergachis, A. B.; Thomas, S.; Thurman, R. E.; Vernot, B.; Vierstra, J.; Vong, S.; Wang, H.; Weaver, M. A.; Yan, Y. Q.; Zhang, M. H.; Akey, J. M.; Bender, M.; Dorschner, M. O.; Groudine, M.; MacCoss, M. J.; Navas, P.; Stamatoyannopoulos, G.; Kaul, R.; Dekker, J.; Stamatoyannopoulos, J. A.; Dunham, I.; Beal, K.; Brazma, A.; Flicek, P.; Herrero, J.; Johnson, N.; Keefe, D.; Lukk, M.; Luscombe, N. M.; Sobral, D.; Vaquerizas, J. M.; Wilder, S. P.; Batzoglou, S.; Sidow, A.; Hussami, N.; Kyriazopoulou-Panagiotopoulou, S.; Libbrecht, M. W.; Schaub, M. A.; Kundaje, A.; Hardison, R. C.; Miller, W.; Giardine, B.; Harris, R. S.; Wu, W.; Bickel, P. J.; Banfai, B.; Boley, N. P.; Brown, J. B.; Huang, H. Y.; Li, Q. H.; Li, J. J.; Noble, W. S.; Bilmes, J. A.; Buske, O. J.; Hoffman, M. M.; Sahu, A. D.; Kharchenko, P. V.; Park, P. J.; Baker, D.; Taylor, J.; Weng, Z. P.; Iyer, S.; Dong, X. J.; Greven, M.; Lin, X. Y.; Wang, J.; Xi, H. L. S.; Zhuang, J. L.; Gerstein, M.; Alexander, R. P.; Balasubramanian, S.; Cheng, C.; Harmanci, A.; Lochovsky, L.; Min, R.; Mu, X. M. J.; Rozowsky, J.; Yan, K. K.; Yip, K. Y.; Birney, E.; Consortium, E. P., An integrated encyclopedia of DNA elements in the human genome. Nature 2012, 489 (7414), 57-74.

123. Pennisi, E., GENOMICS ENCODE Project Writes Eulogy For Junk DNA. Science 2012, 337 (6099), 1159-1161. 
124. Doolittle, W. F., Is junk DNA bunk? A critique of ENCODE. Proceedings of the National Academy of Sciences 2013, 110 (14), 5294-5300.

125. Palazzo, A. F.; Gregory, T. R., The Case for Junk DNA. PLoS genetics 2014, 10 (5), e1004351.

126. Palazzo, A. F.; Lee, E. S., Non-coding RNA: what is functional and what is junk? Front Genet 2015, 6 .

127. Maston, G. A.; Evans, S. K.; Green, M. R., Transcriptional regulatory elements in the human genome. Annu Rev Genom Hum G 2006, 7, 29-59.

128. Patrushev, L. I.; Kovalenko, T. F., Functions of Noncoding Sequences in Mammalian Genomes. Biochemistry-Moscow + 2014, 79 (13), 1442-1469.

129. Subirana, J. A.; Messeguer, X., The most frequent short sequences in non-coding DNA. Nucleic Acids Res 2010, 38 (4), 1172-1181.

130. Lamb, J. C.; Birchler, J. A., The role of DNA sequence in centromere formation. Genome Biol 2003, 4 (5), 214.

131. Slotkin, R. K.; Martienssen, R., Transposable elements and the epigenetic regulation of the genome. Nat Rev Genet 2007, 8 (4), 272-85.

132. Munoz-Lopez, M.; Garcia-Perez, J. L., DNA transposons: nature and applications in genomics. Current genomics 2010, 11 (2), 115-28.

133. Izsvak, Z.; Ivics, Z., Sleeping beauty transposition: biology and applications for molecular therapy. Molecular therapy : the journal of the American Society of Gene Therapy 2004, 9 (2), 147-56.

134. Skipper, K. A.; Andersen, P. R.; Sharma, N.; Mikkelsen, J. G., DNA transposon-based gene vehicles - scenes from an evolutionary drive. Journal of biomedical science 2013, 20,92 .

135. Huang, C. R.; Burns, K. H.; Boeke, J. D., Active transposition in genomes. Annu Rev Genet 2012, 46, 651-75.

136. Mills, R. E.; Bennett, E. A.; Iskow, R. C.; Devine, S. E., Which transposable elements are active in the human genome? Trends Genet 2007, 23 (4), 183-191.

137. Potapova, T.; Gorbsky, G. J., The Consequences of Chromosome Segregation Errors in Mitosis and Meiosis. Biology 2017, 6 (1).

138. Jabs, E. W.; Tuck-Muller, C. M.; Cusano, R.; Rattner, J. B., Studies of mitotic and centromeric abnormalities in Roberts syndrome: implications for a defect in the mitotic mechanism. Chromosoma 1991, 100 (4), 251-61.

139. Sanchez, L.; Martinez, P.; Goyanes, V., Analysis of centromere size in human chromosomes 1, 9, 15, and 16 by electron microscopy. Genome / National Research Council Canada = Genome / Conseil national de recherches Canada 1991, 34 (5), 710-3.

140. Fukagawa, T.; Earnshaw, W. C., The centromere: chromatin foundation for the kinetochore machinery. Dev Cell 2014, 30 (5), 496-508.

141. Bloom, K.; Costanzo, V., Centromere Structure and Function. Progress in molecular and subcellular biology 2017, 56, 515-539.

142. Pluta, A. F.; Mackay, A. M.; Ainsztein, A. M.; Goldberg, I. G.; Earnshaw, W. C., The centromere: hub of chromosomal activities. Science 1995, 270 (5242), 1591-4.

143. McKinley, K. L.; Cheeseman, I. M., The molecular basis for centromere identity and function. Nature reviews. Molecular cell biology 2016, 17 (1), 16-29.

144. Waye, J. S.; Willard, H. F., Nucleotide sequence heterogeneity of alpha satellite repetitive DNA: a survey of alphoid sequences from different human chromosomes. Nucleic Acids Res 1987, 15 (18), 7549-69.

145. Erliandri, I.; Fu, H.; Nakano, M.; Kim, J. H.; Miga, K. H.; Liskovykh, M.; Earnshaw, W. C.; Masumoto, H.; Kouprina, N.; Aladjem, M. I.; Larionov, V., Replication of 
alpha-satellite DNA arrays in endogenous human centromeric regions and in human artificial chromosome. Nucleic Acids Res 2014, 42 (18), 11502-16.

146. McGinty, R. K.; Tan, S., Nucleosome Structure and Function. Chemical reviews 2015, 115 (6), 2255-2273.

147. Bednar, J.; Horowitz, R. A.; Grigoryev, S. A.; Carruthers, L. M.; Hansen, J. C.; Koster, A. J.; Woodcock, C. L., Nucleosomes, linker DNA, and linker histone form a unique structural motif that directs the higher-order folding and compaction of chromatin. $P$ Natl Acad Sci USA 1998, 95 (24), 14173-14178.

148. Bradbury, E. M., K. E. Van Holde. Chromatin. Series in molecular biology. SpringerVerlag, New York. 1988. 530 pp. \$98.00. Journal of Molecular Recognition 1989, 2 (3), i-i.

149. Szerlong, H. J.; Hansen, J. C., Nucleosome distribution and linker DNA: connecting nuclear function to dynamic chromatin structure. Biochemistry and Cell BiologyBiochimie Et Biologie Cellulaire 2011, 89 (1), 24-34.

150. Verdaasdonk, J. S.; Bloom, K., Centromeres: unique chromatin structures that drive chromosome segregation. Nat Rev Mol Cell Bio 2011, 12 (5), 320-332.

151. Furuyama, T.; Henikoff, S., Centromeric Nucleosomes Induce Positive DNA Supercoils. Cell 2009, 138 (1), 104-113.

152. Huang, C. C.; Chang, K. M.; Cui, H.; Jayaram, M., Histone H3-variant Cse4-induced positive DNA supercoiling in the yeast plasmid has implications for a plasmid origin of a chromosome centromere. P Natl Acad Sci USA 2011, 108 (33), 13671-13676.

153. Ocampo, J.; Clark, D. J., A Positive Twist to the Centromeric Nucleosome. Cell reports 2015, 13 (4), 645-646.

154. Peric-Hupkes, D.; Meuleman, W.; Pagie, L.; Bruggeman, S. W. M.; Solovei, I.; Brugman, W.; Graf, S.; Flicek, P.; Kerkhoven, R. M.; van Lohuizen, M.; Reinders, M.; Wessels, L.; van Steensel, B., Molecular Maps of the Reorganization of GenomeNuclear Lamina Interactions during Differentiation. Molecular cell 2010, 38 (4), 603613.

155. Kind, J.; Pagie, L.; Ortabozkoyun, H.; Boyle, S.; de Vries, S. S.; Janssen, H.; Amendola, M.; Nolen, L. D.; Bickmore, W. A.; van Steensel, B., Single-Cell Dynamics of Genome-Nuclear Lamina Interactions. Cell 2013, 153 (1), 178-192.

156. Nemeth, A.; Conesa, A.; Santoyo-Lopez, J.; Medina, I.; Montaner, D.; Peterfia, B.; Solovei, I.; Cremer, T.; Dopazo, J.; Langst, G., Initial Genomics of the Human Nucleolus. PLoS genetics 2010, 6 (3). 